\title{
Ultrasonic assessment of fetal growth: A computer-assisted protocol
}

ALAN STANKIEWICZ, DO, MSC (RAD)

ROBERT L. MEALS, DO, MSC (RAD), FAOCR

The obstetric use of ultrasonography includes the accurate determination of fetal age and early detection of growth aberrations. This involves quantitative efforts involving acquisition and manipulation of measurements of fetal body parts. A review and analysis of the literature, along with a computer protocol, is presented for analyzing fetal growth on the basis of the most commonly measured fetal parameters. The program can be adapted to almost any microcomputer.

Aberrations of fetal growth can be studied quite extensively with ultrasonic imaging. Initially, the main emphasis of ultrasonography in obstetrics was to obtain accurate fetal ages in cases of unknown or unsure menstrual histories. This remains an important task, because it has been estimated that reliable menstrual data can be obtained in only $18 \%$ to $66 \%$ of all pregnancies. ${ }^{1,2}$ Because realtime imaging makes detailed examination of the fetus easier, however, the focus more recently has been on early detection of growth aberrations and fetal anomalies.

Fetal growth can deviate from the normal in a number of ways. Fetal macrosomia is generally defined as weight above the 90th percentile for age. Similarly, intra-uterine growth retardation (IUGR) usually is defined as fetal weight below the 10th percentile for gestational age. These terms sometimes are used synonymously with large or small for gestational age (LGA) or (SGA). IUGR, however, implies an actual constraint on growth potential. Included in the low-weight category would also be the "normal" genetically small fetus. This type of fetus is extremely difficult to distinguish ultrasonically from one with true growth retardation, especially of the symmetric variety.

IUGR can be subdivided into symmetric and asymmetric classes. Symmetric growth retardation affects the skeleton, brain, soft tissue, and abdominal viscera similarly. Etiologies of this class include severe maternal malnutrition, chronic cigarette and alcohol abuse, toxoplasmosis, cytomegalovirus, rubella, and congenital anomalies, as well as chromosomal abnormalities. ${ }^{3,4}$ This is also referred to as the "low profile" type of IUGR. ${ }^{5}$

In contrast, asymmetric IUGR primarily affects the visceral and subcutaneous soft tissues while showing relative skeleton- and brain-sparing effects. This type of IUGR results from uteroplacental vascular insufficiency ${ }^{4}$ and is associated with chronic maternal hypertension, severe diabetes mellitus, chronic renal disease, collagen vascular disease, and placental infarction. Seeds ${ }^{3}$ suggests that asymmetric IUGR is actually a fetal adaptation to hypoxia, which results in preferential blood flow to the brain and decreased flow to the viscera (which would also explain the association of IUGR with oligohydramnios secondary to decreased renal perfusion).

The liver, one of the organs primarily affected by this type of IUGR, is decreased in size even early in the process (secondarily to decreased glycogen stores); the brain size is not affected until later, which causes the so-called late flattening of the biparietal diameter growth curve ${ }^{3,4}$ Measurement of the abdominal circumference (AC) at the level of the liver, therefore, demonstrates both liver size and subcutaneous fat, and when compared to head or leg size, should be a good indicator of asymmetric IUGR. 
The relative frequency of each type of IUGR varies in the literature, with estimates of the asymmetric variety accounting for $33 \%$ to $70 \%$. $^{3,6,7}$ The distinction is further complicated, however, by overlap from severe, long-standing uteroplacental insufficiency that actually causes the symmetric type of IUGR.

Fetal macrosomia also can be categorized into symmetric and asymmetric varieties. Symmetric macrosomia involves proportionally increased growth and is considered to be secondary to genetic large stature, whereas asymmetric macrosomia mainly affects the soft tissue and visceral mass (with relative sparing of the brain and skeleton) and is frequently associated with class $\mathrm{A}$ to $\mathrm{C}$ maternal diabetics. ${ }^{8}$ Other causative factors in macrosomia include high maternal birth weight, obesity, increasing parity, and maternal age..$^{9,10}$

The necessity to detect growth aberrations in utero is obvious when one considers the associated perinatal mortality and morbidity. Studies have shown that about $20 \%$ of all stillbirths show evidence of growth retardation, ${ }^{11}$ and that perinatal mortality is increased four to eight times in SGA $v$ appropriate-for-gestational-age infants. ${ }^{12,13}$ Perinatal morbidity associated with IUGR includes meconium aspiration, intrapartum fetal distress, neonatal hypoglycemia, polycythemia, and hypocalcemia; IUGR combined with prematurity is especially deleterious. $^{3}$

Usher and McLean ${ }^{14}$ asserted that $0.27 \%$ of all perinatal deaths can be attributed solely to IUGR, and that $70 \%$ of these can be prevented by early intrauterine diagnosis. Macrosomia also carries an increased risk of perinatal mortality; associated morbidity includes low Apgar scores, shoulder dystocia, asphyxia, and skeletal and nerve injury during delivery. $8,10,15,16$ Many would advocate cesarean delivery of the macrosomic infant.

Detection of fetal growth aberrations is largely a quantitative endeavor involving the acquisition and manipulation of various fetal body part measurements. Much has been written concerning this task, and, fortunately, the early articles continue to retain their utility in this regard, for studies have shown no statistical difference in measurements obtained by static, real-time, bistable, or gray-scale imaging modes. ${ }^{17-19}$

The available information and protocols, however, often involve many time-consuming mathematical calculations and comparisons, some of which are quite complex and would take an exorbitant amount of time from a busy clinical practice. Frequently, therefore, only the "quick and easy" methods are used to screen for growth aberrations, and a wealth of valuable information is
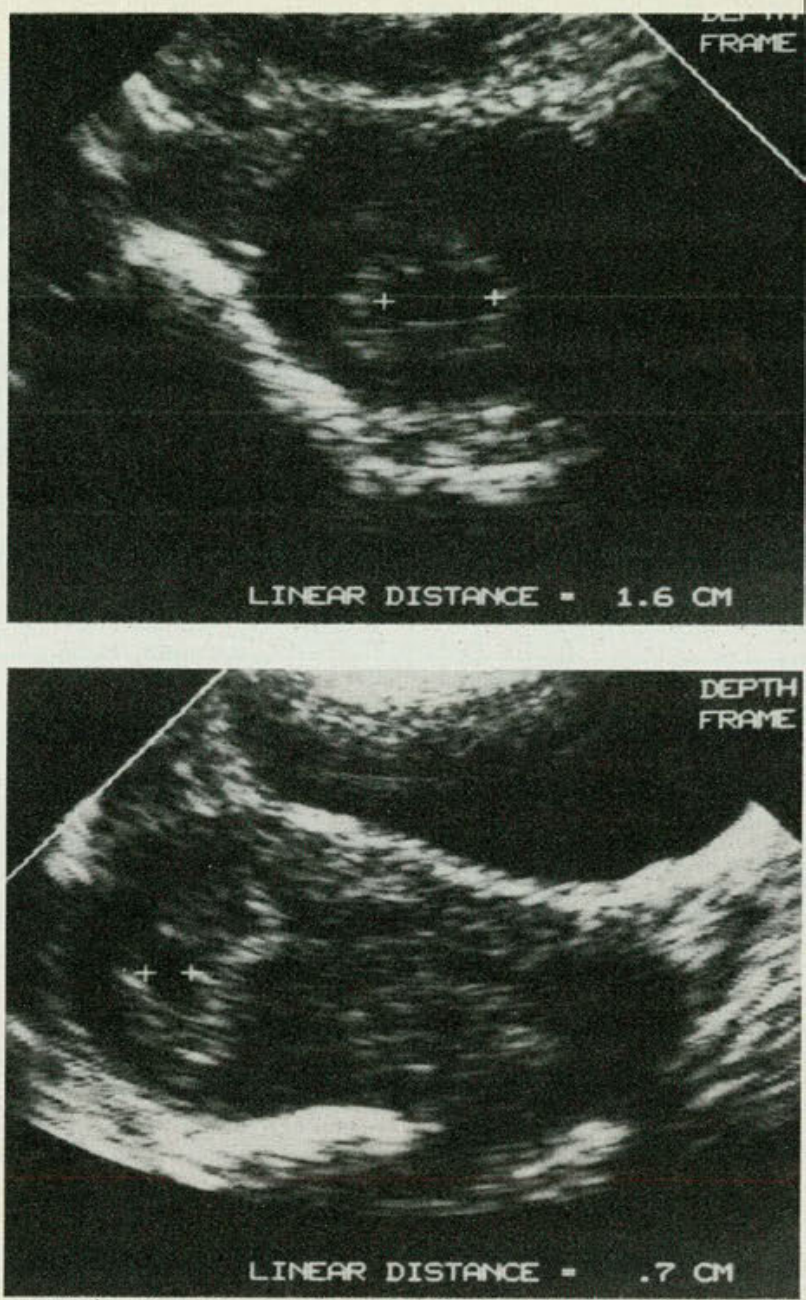

Fig 1. Axial scan (A) is used to obtain transverse diameter of gestational sac, and sagittal scan $(B)$ is used to obtain AP and longitudinal diameters.

ignored simply because it is too cumbersome to use on a routine clinical basis.

The purpose of this paper, therefore, is to develop a protocol to analyze fetal growth based on single or serial ultrasonographic examinations using the available information in the literature to date. From this protocol, a computer program will be written to manipulate and analyze the commonly derived data from typical fetal ultrasonographic examinations. With the use of an inexpensive microcomputer, this analysis can be expedited to save time for the ultrasonographer, while providing uniquely valuable information concerning fetal growth.

\section{Methods of growth analysis}

The most commonly measured parameters of fetal growth include the biparietal diameter (BPD), head circumference $(\mathrm{HC})$, abdominal circumference 


\begin{tabular}{|cccc|}
\hline \multicolumn{4}{|c|}{ TABLE 1. AVERAGE GESTATIONAL SAC DIAMETER (GSD) $V$ GES- } \\
TATIONAL AGE (GA) ${ }^{*}$ " \\
\hline GSD $(\mathrm{mm})$ & GA (wk) & GSD $(\mathrm{mm})$ & GA (wk) \\
\hline 10.0 & 5.0 & 36.0 & 8.8 \\
11.0 & 5.2 & 37.0 & 8.9 \\
12.0 & 5.3 & 38.0 & 9.0 \\
13.0 & 5.5 & 39.0 & 9.2 \\
14.0 & 5.6 & 40.0 & 9.3 \\
15.0 & 5.8 & 41.0 & 9.5 \\
16.0 & 5.9 & 42.0 & 9.6 \\
17.0 & 6.0 & 43.0 & 9.7 \\
18.0 & 6.2 & 44.0 & 9.9 \\
19.0 & 6.3 & 45.0 & 10.0 \\
20.0 & 6.5 & 46.0 & 10.2 \\
21.0 & 6.6 & 47.0 & 10.3 \\
22.0 & 6.8 & 48.0 & 10.5 \\
23.0 & 6.9 & 49.0 & 10.6 \\
24.0 & 7.0 & 50.0 & 10.7 \\
25.0 & 7.2 & 51.0 & 10.9 \\
26.0 & 7.3 & 52.0 & 11.0 \\
27.0 & 7.5 & 53.0 & 11.2 \\
28.0 & 7.6 & 54.0 & 11.3 \\
29.0 & 7.8 & 55.0 & 11.5 \\
30.0 & 7.9 & 56.0 & 11.6 \\
31.0 & 8.0 & 57.0 & 11.7 \\
32.0 & 8.2 & 58.0 & 11.9 \\
33.0 & 8.3 & 59.0 & 12.0 \\
34.0 & 8.5 & 60.0 & 12.2 \\
35.0 & 8.6 & & \\
& & & \\
\hline Derived from Hellman and associates ${ }^{22}$ & & \\
& & & \\
\hline
\end{tabular}

(AC), femur length (FL), crown-rump length (CRL), and gestational sac size. Other less commonly used measurements are outer orbital diameter, abdominal diameter, chest diameter, thigh and calf circumferences, total intrauterine volume, and other extremity lengths. All these parameters have been compared in many different ways by numerous authors in attempts to monitor fetal growth. The most accurate ultrasonic indicator of fetal age appears to be the CRL prior to 14 weeks' gestation (a 2 SD range of \pm 4.7 days). ${ }^{20}$

Campbell and associates, ${ }^{21}$ however, recently have claimed greatest accuracy using BPD measurement at 12 to 18 weeks' gestation. Many formulas employing the parameters mentioned have been derived to estimate fetal weight. Various ratios have been analyzed for their ability to detect abnormal body proportionalities. Growth rates of specific body parts have also been studied. These methods now will be examined for their utility in developing the growth analysis protocol.

\section{Sac diameter}

A linear relationship between age (prior to 13 weeks) and gestational sac diameter (GSD) was found by Hellman and coworkers. ${ }^{22}$ Measuring the anteroposterior and longitudinal diameters in the sagittal plane and the transverse diameter in the axial plane (Fig 1), they obtained average GSD. The following regression equation to determine gestational age (GA) is derived from theirs, which used 38 measurements from 25 patients:

Formula 1

$$
\mathrm{GA}(\mathrm{wk})=\frac{\operatorname{Avg} \mathrm{GSD}(\mathrm{mm})+25.43}{7.02}
$$

Table 1 is derived from this equation and can be used to estimate GA in early pregnancy.

\section{Crown-rump length (CRL)}

In 1975 , Robinson and Fleming ${ }^{20}$ reported on the relationship of CRL to menstrual age from 6 to 14 weeks' gestation. They performed a regression analysis on 334 CRL measurements, which was corrected for errors in beam width $(1 \mathrm{~mm})$, scale factor $(+$ $3 \%$, and velocity of sound in tissue $(1,540 \mathrm{~m} / \mathrm{s} v$ the actual $1,530 \mathrm{~m} / \mathrm{s}$ ). It is assumed that recent technology is producing more accurate ultrasound machines; however, these machines are still calibrated at a velocity of $1,540 \mathrm{~m} / \mathrm{s}$, so this correction should be discarded when estimating GA from CRL.

Derived from Robinsion and Fleming, ${ }^{20}$ the following equation was used in the construction of Table 2:

\section{Formula 2}

$\mathrm{GA}(\mathrm{wk})=\frac{8.052 \sqrt{\mathrm{CRL}(\mathrm{mm})+1+0.03 \mathrm{CRL}(\mathrm{mm})}+23.73}{7}$

The technique of CRL measurement is illustrated in Fig 2.

\section{Head size}

The BPD is the most commonly measured fetal parameter and almost always can be obtained with real-time imaging. Standardized planes of measurement have been suggested to improve reliability, ${ }^{23-25}$ and include simultaneous visualization of the thalamus and cavum septum pellucidum (Fig 3 ). Numerous studies correlating BPD with age have been performed. In 1980, Kurtz and associates ${ }^{26}$ compiled data from many of these studies and constructed a composite BPD table from 12 weeks' gestation to term. More recently, Selbing and Kjessler, ${ }^{27}$ emphasizing earlier determinations, correlated measurements of BPD with age. Table 3 reflects compiled information from these two studies; Selbing and Kjessler's data are used for BPD of 11-21 mm, and the data from Kurtz and associ- 


\begin{tabular}{|c|c|c|c|}
\hline CRL (mm) & GA (wk) & CRL (mm & GA (wk) \\
\hline 5 & 6.2 & 43 & 11.1 \\
\hline 6 & 6.5 & 44 & 11.2 \\
\hline 7 & 6.7 & 45 & 11.3 \\
\hline 8 & 6.9 & 46 & 11.4 \\
\hline 9 & 7.1 & 47 & 11.5 \\
\hline 10 & 7.3 & 48 & 11.6 \\
\hline 11 & 7.4 & 49 & 11.6 \\
\hline 12 & 7.6 & 50 & 11.7 \\
\hline 13 & 7.8 & 51 & 11.8 \\
\hline 14 & 7.9 & 52 & 11.9 \\
\hline 15 & 8.1 & 53 & 12.0 \\
\hline 16 & 8.2 & 54 & 12.0 \\
\hline 17 & 8.3 & 55 & 12.1 \\
\hline 18 & 8.5 & 56 & 12.2 \\
\hline 19 & 8.6 & 57 & 12.3 \\
\hline 20 & 8.7 & 58 & 12.4 \\
\hline 21 & 8.9 & 59 & 12.4 \\
\hline 22 & 9.0 & 60 & 12.5 \\
\hline 23 & 9.1 & 61 & 12.6 \\
\hline 24 & 9.2 & 62 & 12.7 \\
\hline 25 & 9.3 & 63 & 12.7 \\
\hline 26 & 9.5 & 64 & 12.8 \\
\hline 27 & 9.6 & 65 & 12.9 \\
\hline 28 & 9.7 & 66 & 12.9 \\
\hline 29 & 9.8 & 67 & 13.0 \\
\hline 30 & 9.9 & 68 & 13.1 \\
\hline 31 & 10.0 & 69 & 13.2 \\
\hline 32 & 10.1 & 70 & 13.2 \\
\hline 33 & 10.2 & 71 & 13.3 \\
\hline 34 & 10.3 & 72 & 13.4 \\
\hline 35 & 10.4 & 73 & 13.4 \\
\hline 36 & 10.5 & 74 & 13.5 \\
\hline 37 & 10.6 & 75 & 13.6 \\
\hline 38 & 10.7 & 76 & 13.6 \\
\hline 39 & 10.8 & 77 & 13.7 \\
\hline 40 & 10.9 & 78 & 13.8 \\
\hline 41 & 11.0 & 79 & 13.8 \\
\hline 42 & 11.0 & & \\
\hline
\end{tabular}

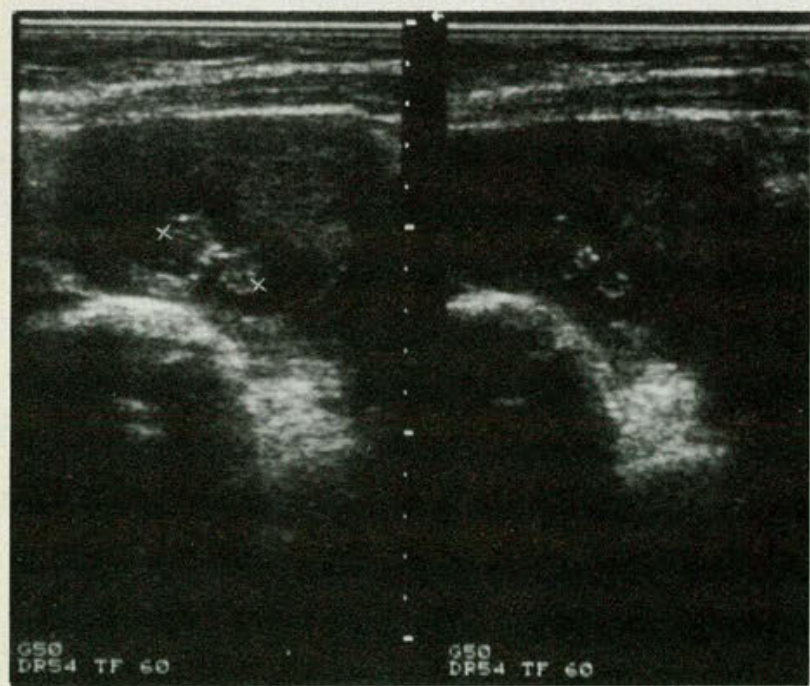

Fig 2. Technique of CRL measurement. The scanning plane is oriented parallel to longitudinal axis of fetus. Note that limb buds or yolk sac must not be included.

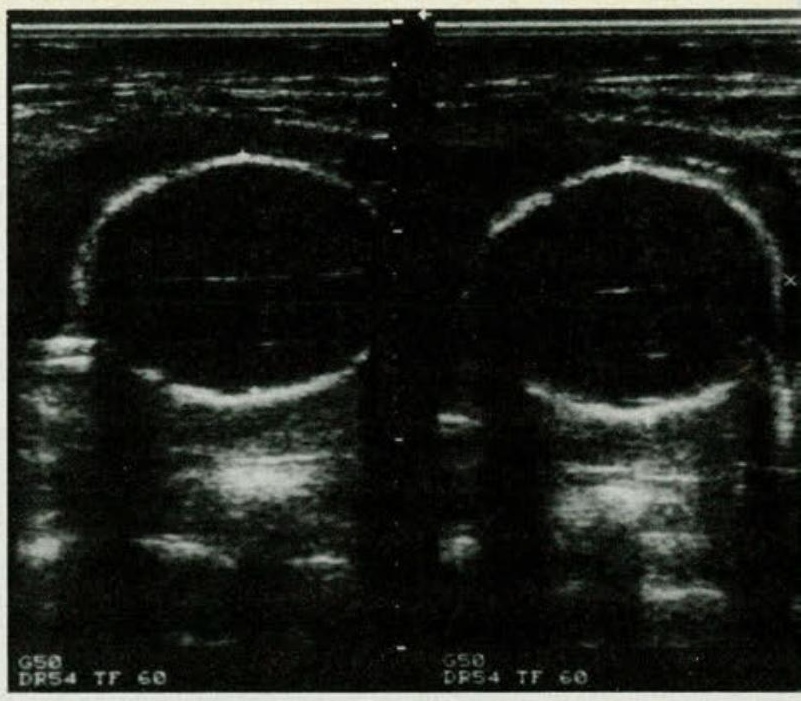

Fig 3. $B P D(A)$ is measured from leading edges of opposite sides of skull. HC, however, is measured along outer border of skull, so long and short diameters used in deriving circumference are measured from outer to outer surfaces $(B)$.

ates are used for BPD of 22 to $98 \mathrm{~mm}$.

Head circumference (HC) is also a commonly measured fetal parameter and should be a more reliable indicator of GA than BPD. ${ }^{28}$ This is because variations in fetal head shapes (given constant volumes) would tend to affect BPD, but not circumference. $\mathrm{HC}$ is imaged in the same plane as the BPD (Fig 3) and can be obtained through the use of an electronic digitizer, a map reader, or by mathematical methods, which assume that the head conforms to the shape of an ellipse. Because of limited access to electronic digitizers and relative awkwardness of map readers, mathematical methods are the most often used.

Hadlock and coauthors ${ }^{29}$ have concluded that the following approximation is sufficient for clinical use:

\section{Formula 3}

$$
\text { Circumference }=1.57\left(d_{1}+d_{2}\right)
$$

(where $d_{1}$ and $d_{2}$ are the long and short axes of an ellipse).

DeVore and Platt, ${ }^{30}$ however, have pointed out that significant errors in age estimation can occur with this approximation when there is dolichocephaly, especially with increasing age. The circumference of an ellipse can be expressed as an infinite series, 


\begin{tabular}{|c|c|c|c|c|c|}
\hline BPD & Mean GA & \pm 2 SD Range & BPD & Mean GA & \pm 2 SD Range \\
\hline 11 & 10.2 & $9.3-10.9$ & 55 & 22.2 & $20.0-24.4$ \\
\hline 12 & 10.3 & $9.5-11.1$ & 56 & 22.5 & $20.3-24.7$ \\
\hline 13 & 10.5 & $9.7-11.3$ & 57 & 22.8 & $20.7-24.9$ \\
\hline 14 & 10.7 & $9.9-11.5$ & 58 & 23.2 & $21.1-25.3$ \\
\hline 15 & 10.9 & $10.1-11.7$ & 59 & 23.5 & $21.6-25.4$ \\
\hline 16 & 11.1 & $10.5-11.7$ & 60 & 23.8 & $21.9-25.7$ \\
\hline 17 & 11.3 & $10.7-11.9$ & 61 & 24.4 & $22.3-26.1$ \\
\hline 18 & 11.6 & $11.0-12.2$ & 62 & 24.6 & $22.8-26.4$ \\
\hline 19 & 11.8 & $11.2-12.4$ & 63 & 24.9 & $23.1-26.7$ \\
\hline 20 & 12.0 & $11.4-12.6$ & 64 & 25.3 & $23.5-27.1$ \\
\hline 21 & 12.3 & $11.6-13.0$ & 65 & 25.6 & $23.8-27.4$ \\
\hline 22 & 12.7 & $12.1-13.3$ & 66 & 26.0 & $24.2-27.8$ \\
\hline 23 & 13.0 & $12.3-13.7$ & 67 & 26.4 & $24.7-28.1$ \\
\hline 24 & 13.2 & $12.5-13.9$ & 68 & 26.7 & $25.0-28.4$ \\
\hline 25 & 13.5 & $12.8-14.2$ & 69 & 27.1 & $25.5-28.7$ \\
\hline 26 & 13.7 & $13.0-14.4$ & 70 & 27.5 & $26.0-29.0$ \\
\hline 27 & 14.0 & $13.3-14.7$ & 71 & 27.9 & $26.4-29.4$ \\
\hline 28 & 14.3 & $13.4-15.2$ & 72 & 28.3 & $27.0-29.6$ \\
\hline 29 & 14.6 & $13.7-15.5$ & 73 & 28.7 & $27.4-30.0$ \\
\hline 30 & 14.8 & $13.9-15.7$ & 74 & 29.1 & $27.9-30.3$ \\
\hline 31 & 15.1 & $14.1-16.1$ & 75 & 29.5 & $28.3-30.7$ \\
\hline 32 & 15.3 & $14.3-16.3$ & 76 & 30.0 & $28.8-31.2$ \\
\hline 33 & 15.6 & $14.5-16.7$ & 77 & 30.3 & $29.0-31.6$ \\
\hline 34 & 15.9 & $14.8-17.0$ & 78 & 30.8 & $29.3-32.3$ \\
\hline 35 & 16.2 & $15.0-17.4$ & 79 & 31.1 & $29.5-32.7$ \\
\hline 36 & 16.4 & $15.2-17.6$ & 80 & 31.6 & $29.9-33.3$ \\
\hline 37 & 16.7 & $15.4-18.0$ & 81 & 32.1 & $30.4-33.8$ \\
\hline 38 & 17.0 & $15.7-18.3$ & 82 & 32.6 & $30.9-34.3$ \\
\hline 39 & 17.3 & $15.8-18.8$ & 83 & 33.0 & $31.2-34.8$ \\
\hline 40 & 17.6 & $16.1-19.1$ & 84 & 33.4 & $31.5-35.3$ \\
\hline 41 & 17.9 & $16.2-19.6$ & 85 & 34.0 & $31.9-36.1$ \\
\hline 42 & 18.1 & $16.2-20.0$ & 86 & 34.3 & $32.2-36.4$ \\
\hline 43 & 18.4 & $16.3-20.5$ & 87 & 35.0 & $33.1-36.9$ \\
\hline 44 & 18.8 & $16.5-21.1$ & 88 & 35.4 & $33.5-37.3$ \\
\hline 45 & 19.1 & $16.5-21.7$ & & 36.1 & $34.3-37.9$ \\
\hline 46 & 19.4 & $17.0-21.8$ & 90 & 36.6 & $34.8-38.4$ \\
\hline 47 & 19.7 & $17.4-22.0$ & 91 & 37.2 & $35.6-38.8$ \\
\hline 48 & 20.0 & $17.8-22.2$ & 92 & 37.8 & $36.5-39.1$ \\
\hline 49 & 20.3 & $18.2-22.4$ & 93 & 38.8 & $37.6-40.0$ \\
\hline 50 & 20.6 & $18.7-22.5$ & 94 & 39.0 & $37.7-40.3$ \\
\hline 51 & 20.9 & $19.0-22.8$ & 95 & 39.7 & $38.2-41.2$ \\
\hline 52 & 21.2 & $19.1-23.3$ & 96 & 40.6 & $39.1-42.1$ \\
\hline 53 & 21.5 & $19.4-23.6$ & 97 & 41.0 & $39.7-42.3$ \\
\hline 54 & 21.9 & $19.7-24.1$ & 98 & 41.8 & $40.2-43.4$ \\
\hline
\end{tabular}

but a very good approximation is given by the following formula ${ }^{31}$ :

\section{Formula 4}

$$
\text { Circumference }=\pi(\mathrm{a}+\mathrm{b}) \frac{64-3 \mathrm{R}^{4}}{64-16 \mathrm{R}^{2}}
$$

(where $\mathrm{a}$ and $\mathrm{b}$ are one half the long and short axes, respectively, and $R=(a-b) /(a+b)$. The length of this formula is of no consequence to the clinician, because all mathematical calculations will be performed by the computer.

The BPD measurement is customarily taken from "outer to inner" borders of the opposing skull surfaces, whereas the "outer to outer" measurement of the transverse head is needed to calculate $\mathrm{HC}$, because $\mathrm{HC}$ customarily is measured along the outer surface of the skull (Fig 3). If, therefore, the proper calvarial thickness could be added to the BPD, only one measurement of the transverse head diameter would be needed in the routine ultrasonographic examination.

Doubilet and Greenes ${ }^{32}$ have developed such a regression formula of calvarial thickness as a function of BPD. Skull thickness appears to vary slightly, however, in relation to the particular type of ultrasound machine used (apparent thickness seems to be related to resolution), and regression 
formulas such as these should be developed for use at each individual laboratory.

For the purpose of this protocol, the following equation is derived from data from 74 fetuses between 24 and 42 weeks' gestation and uses least squares regression analysis:

\section{Formula 5}

Skull thickness $(\mathrm{mm})=2.451-0.04732 \mathrm{BPD}+$ $0.0011 \mathrm{BPD}^{2}-7.016 \times 10^{-6}$ $\mathrm{BPD}^{3}$

Hadlock and associates ${ }^{33}$ have reported one of the largest studies to date relating $\mathrm{HC}$ to gestational age. Using cross-sectional data of 400 fetuses from 15 to 41 weeks' gestation, they derived the following equation:

\section{Formula 6}

$\mathrm{GA}(\mathrm{wk})=8.8+0.055 \mathrm{HC}(\mathrm{mm})+2.8 \times 10^{-7} \mathrm{HC}^{3}(\mathrm{~mm})$

The following first-order regression equation is derived from their "method 2" variability data:

\section{Formula 7}

$$
2 \mathrm{SD}(\mathrm{wk})=0.0883 \mathrm{GA}(\mathrm{wk})-0.125
$$

HC can also be used to "correct" the BPD in cases of abnormal head shape. Head shape can be defined in terms of the cephalic index (CI), which is expressed as the transverse head diameter (measured outer to outer surface) divided by the occipitofrontal diameter (OFD), (outer to outer), imaged in the same plane as BPD. Mean CI remains constant from 14 to 40 weeks at $78.3 \%$, with 1 SD of $4.4 \% .^{28}$

BPD measurements of heads with cephalic indices outside this range yield inaccurate estimations of gestational age. Doubilet and Greenes, ${ }^{32}$ therefore, have proposed methods to correct the BPD to what it would be if the head were normally shaped $(\mathrm{CI}=78.3 \%)$. Thus, on the assumption of constant circumference or cross-sectional area, the head can be reshaped mathematically to obtain a "corrected BPD."

Therefore, even in cases of dolichocephaly (CI $<73.9 \%$ ) or brachycephaly (CI $>82.7 \%$ ), the BPD can still be used for accurate assessment of GA. In fact, there is no reason why corrected BPD should not always be used to obtain more accurate estimations of age, no matter how slightly the CI deviates from the mean. These corrected BPDs may be used in any formula or table that was originally conceived from plain BPD measurements alone, because results of studies based on large numbers of fetuses will reflect that of the average shaped head $(\mathrm{CI}=78.3 \%)$.

Doubilet and Greenes ${ }^{32}$ found no statistically significant difference in age estimation using area $v$ circumference correction methods; however, they advocated area correction because the area formula is simpler and $\mathrm{HC}$ does not have to be obtained. However, because $\mathrm{HC}$ is obtained routinely and the computer is assigned the task of all calculations, circumference-corrected (cir corr) BPD will be used in this protocol. It can also be argued that as abnormal compressive forces act to produce dolichocephaly (as may occur with breech presentation, twins, and oligohydramnios), the fetal brain will not only elongate in a fronto-occipital direction but also in a craniocaudal direction; as a result, theoretically, the cross-sectional area would decrease while the circumference would remain unchanged. Given equation 4 and an average CI of $78.3 \%$, it can be shown that:

\section{Formula 8}

$$
\mathrm{BPD} \text { cir corr }=0.27855 \mathrm{HC}-\text { calvarial thickness }
$$

\section{Femur length $(F L)$}

The fetal FL has been shown to correlate well with $\mathrm{GA}^{34-38}$ and is also useful in detecting aberrations of growth. ${ }^{39-43} \mathrm{~A}$ strong relation between $\mathrm{FL}$ and crown-heel length has also been established. ${ }^{44}$ Based on FL from measurements of 361 fetuses from 14 to 42 weeks' gestation, Hadlock and associates $^{37}$ have developed the following regression formula for GA:

\section{Formula 9}

$\mathrm{GA}(\mathrm{wk})=10.35+0.246 \mathrm{FL}(\mathrm{mm})+0.0017 \mathrm{FL}^{2}(\mathrm{~mm})$

Two standard deviations using this equation is as follows: at 12 to 18 weeks $=1.4$ weeks; at 18 to 24 weeks $=1.8$ weeks; at 24 to 30 weeks $=2.1$ weeks; at 30 to 36 weeks $=3.0$ weeks; at 36 to 42 weeks $=3.1$ weeks.

Measurement of the fetal FL (Fig 4) is taken along the long axis of the bone and should not include the distal femoral epiphysis or femoral neck. 


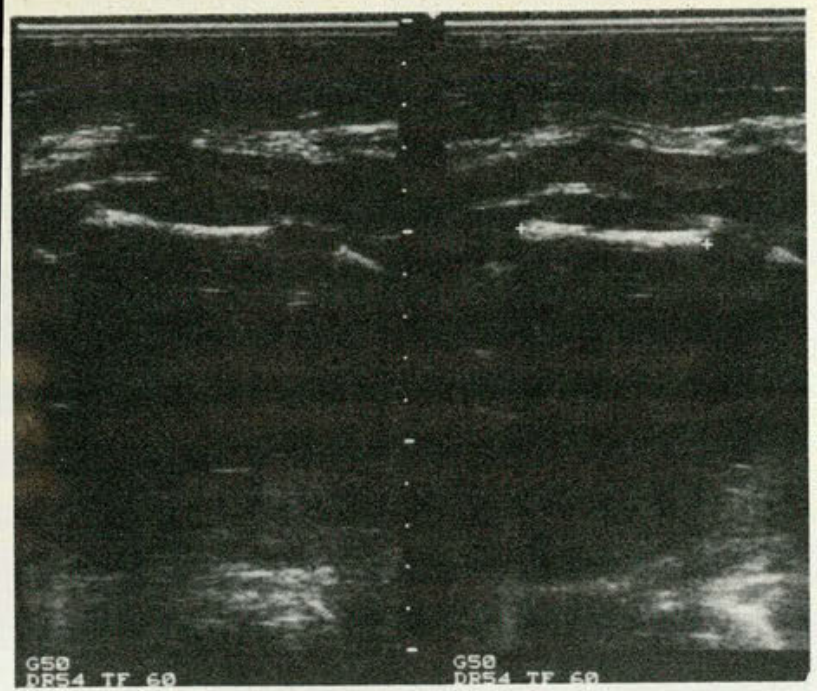

Fig 4. Fetal FL measurement.

\section{Abdominal circumference ( $A C$ )}

Extensive studies $6,15,37,41-43,45-50$ have shown that the fetal AC is useful as a parameter of gestational age and growth aberrations. The technique of measurement is similar to that for $\mathrm{HC}$, and, again, mathematical methods employing the $\mathrm{AP}$ and transverse diameters can be used similarly (Fig 5 ). The following equation derived by Hadlock and coworkers, ${ }^{50}$ who used measurements of 400 fetuses from 15 to 41 weeks' gestation, relates $\mathrm{AC}$ to gestational age:

\section{Formula 10}

$\mathrm{GA}(\mathrm{wk})=7.607+0.07645 \mathrm{AC}(\mathrm{mm})+3.93 \times 10^{-5} \mathrm{AC}^{2}$ $(\mathrm{mm})$

The variability ( $2 \mathrm{SD}$ ) with this equation is as follows: at 12 to 18 weeks $=1.9$ weeks; at 18 to 24 weeks $=2.0$ weeks; at 24 to 30 weeks $=2.2$ weeks; at 30 to 36 weeks $=3.0$ weeks; at 36 to 42 weeks $=2.5$ weeks;

Improved estimates of GA in the second and third trimesters can be obtained using measurements of $\mathrm{FL}, \mathrm{BPD}, \mathrm{AC}$, and $\mathrm{HC}$ in combination. It is not uncommon, however, to be unable to image some of these parameters in certain cases because of peculiarities in fetal position. Several complex equations have been derived using multiple regression analysis of these parameters; however, Hadlock and associates ${ }^{37}$ have shown no statistically significant improvement with these methods over the simple technique of averaging the age estimates based on these individual parameters, so the averaging technique will be employed in this protocol.

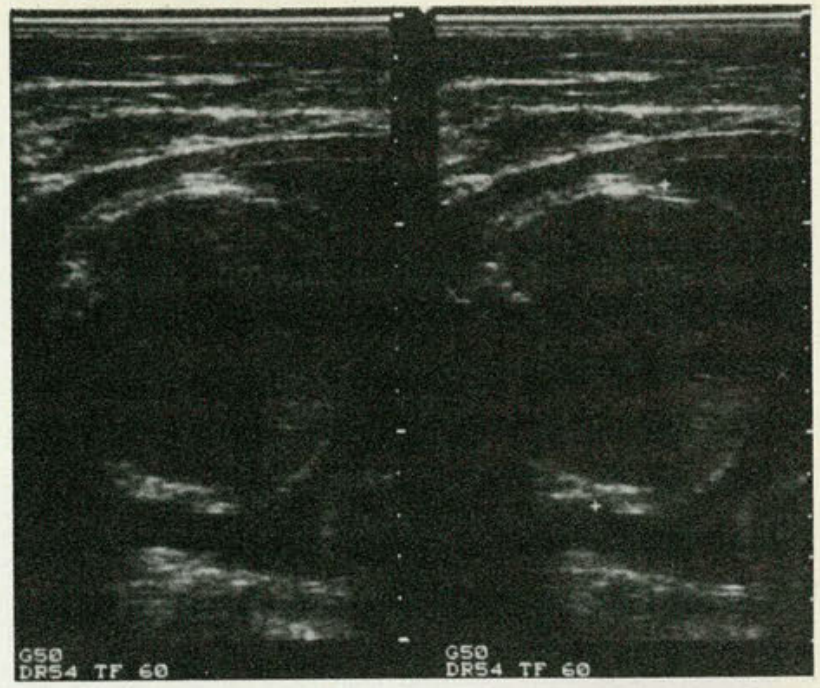

Fig 5. Abdominal circumference $(A C)$ is determined from equation 4 using AP and transverse diameters at level of umbilical vein.

\section{Body part disproportionalities}

Numerous studies have compared these parameters in attempts to detect disproportionate fetal growth. Many of these comparisons take advantage of the relative brain- and skeleton-sparing effects of the asymmetric varieties of IUGR and macrosomia. The most useful of these would be the ones that can be employed without knowledge of GA. Such a method involves the use of the FL/AC ratio. Hadlock and associates have suggested that a FL/AC ratio greater than 0.235 be used as a screening device to detect $\mathrm{IUGR}^{41}$ and a ratio less than 0.205 be used to detect macrosomia. ${ }^{42}$ This ratio can be employed from 22 weeks' gestation to term and is independent of age during this period.

Hohler and Quetel ${ }^{39}$ have studied the FL/BPD ratio and derived the following equation, which is valid from 23 weeks' gestation to term:

\section{Formula 11}

$$
\mathrm{FL} / \mathrm{BPD}=0.73+0.002 \mathrm{GA}(w \mathrm{w})
$$

They suggested the use of a $90 \%$ confidence level $( \pm 0.08)$ to screen for such entities as dwarfism, hydrocephalus, microcephaly, and measurement errors. This ratio is not entirely independent of gestational age, so an age estimate must be obtained before it is employed.

The use of $\mathrm{HC} / \mathrm{AC}$ ratio (from 13 to 40 weeks) to detect IUGR was originally described by Campbell and Thoms. ${ }^{45}$ Crane and Kopta ${ }^{46}$ later confirmed the utility of this ratio, which is not in- 


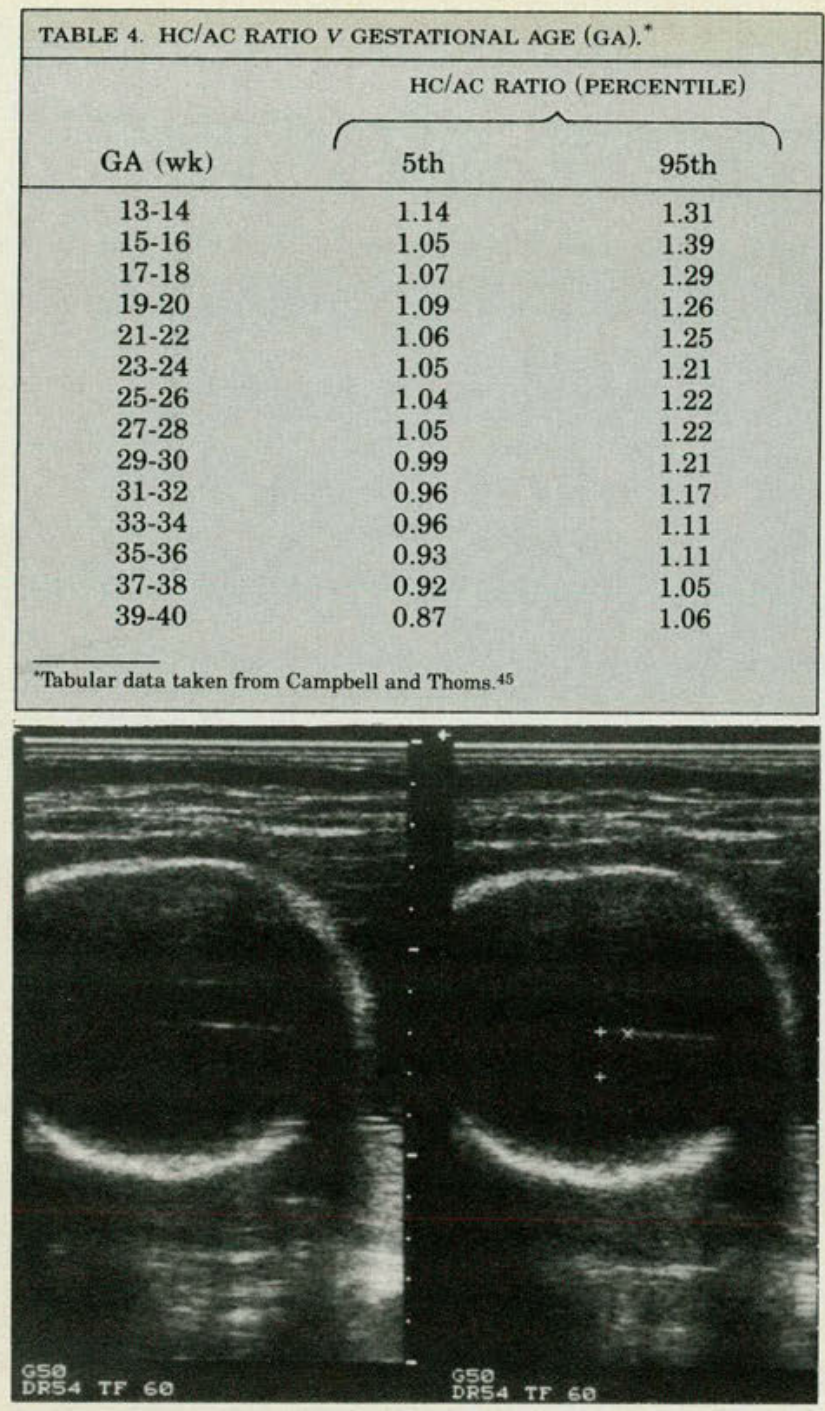

Fig 6. Lateral ventricular width ( $L V W$ ) is measured from midline echo to lateral wall of far lateral ventricle. Hemisphere width $(H W)$ is measured from midline echo to leading edge of far skull surface, Lateral ventricular ratio $=L V W / H W$.

dependent of age. The $\mathrm{HC} / \mathrm{AC}$ ratio is primarily useful in detecting asymmetric types of growth aberrations or in distinguishing the asymmetric and symmetric forms in cases of known IUGR. The 5 th and 95th percentile confidence limits, as determined by Campbell and Thoms, ${ }^{45}$ are reproduced here for tabular entry into the computer (Table 4).

In attempts to detect fetal hydrocephalus, normal ranges of the lateral ventricular ratio (LVR) have been established. ${ }^{51,52}$ The LVR is defined as the lateral ventricular width divided by the hemispheric width (Fig 6) and is a function of GA. The data of Johnson and coworkers ${ }^{51}$ and Pretorius and colleagues ${ }^{52}$ have been compiled in Table 5 by averaging their upper limits of normal LVR to enable detection of ventriculomegaly.

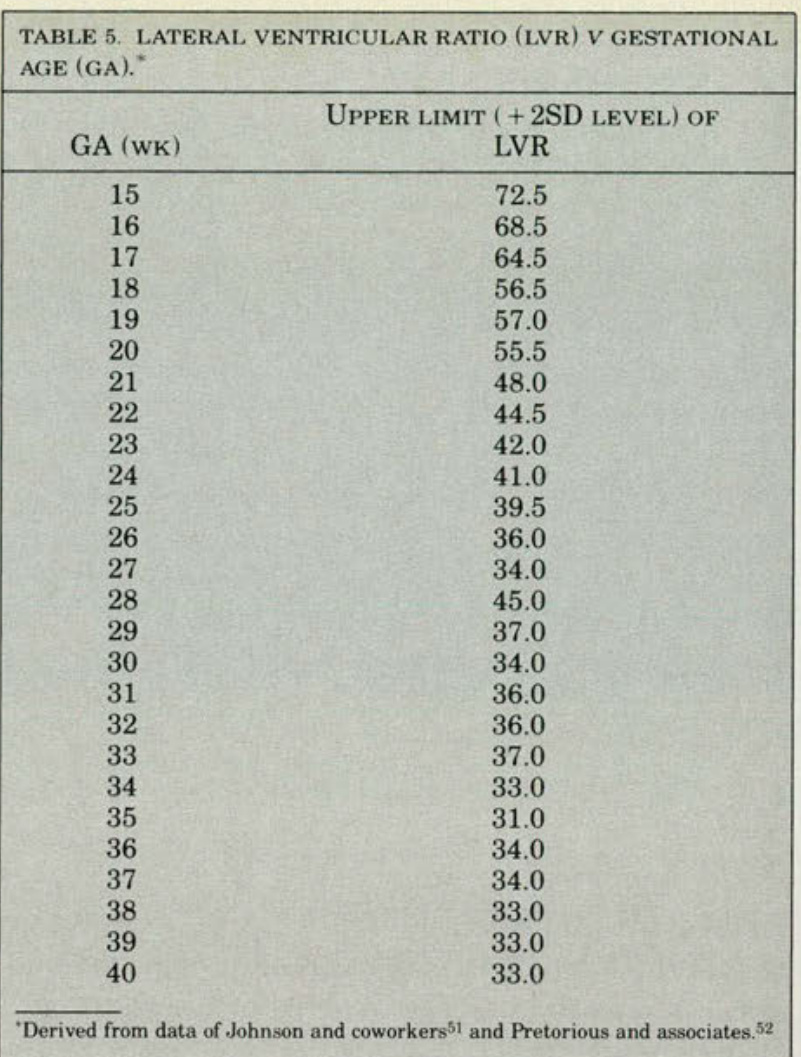

\section{$B P D$ and $F L$ growth rates}

Serial sonography (at 3 to 10 week intervals) can provide additional information concerning fetal growth. The BPD growth rate during pregnancy has been thoroughly investigated ${ }^{53,54}$ and proved useful ${ }^{55}$ in the detection of IUGR. Levi and Smets's data, ${ }^{54}$ which are based on 3,032 measurements of 1,011 patients from 15 to 43 weeks' gestation, are partially reproduced in Table 6 .

Clinically, the BPD growth rate can be determined easily by dividing the change in BPD by the number of weeks elapsed between two serial examinations. The midpoint in time between these two examinations is taken as the age at which this growth rate occurred. This point is then used as a reference in Table 6 to determine whether the BPD growth rate is within the 10 th to 90 th percentile range.

It is probably wise to allow at least 3 weeks to pass between serial examinations, because measurement errors have a much greater effect on the calculation of growth rates if based on small changes in BPD. It is also prudent not to base the growth rate on examinations more than about 10 weeks apart, because of the normally changing $\mathrm{BPD}$ growth rate during pregnancy and the assump- 


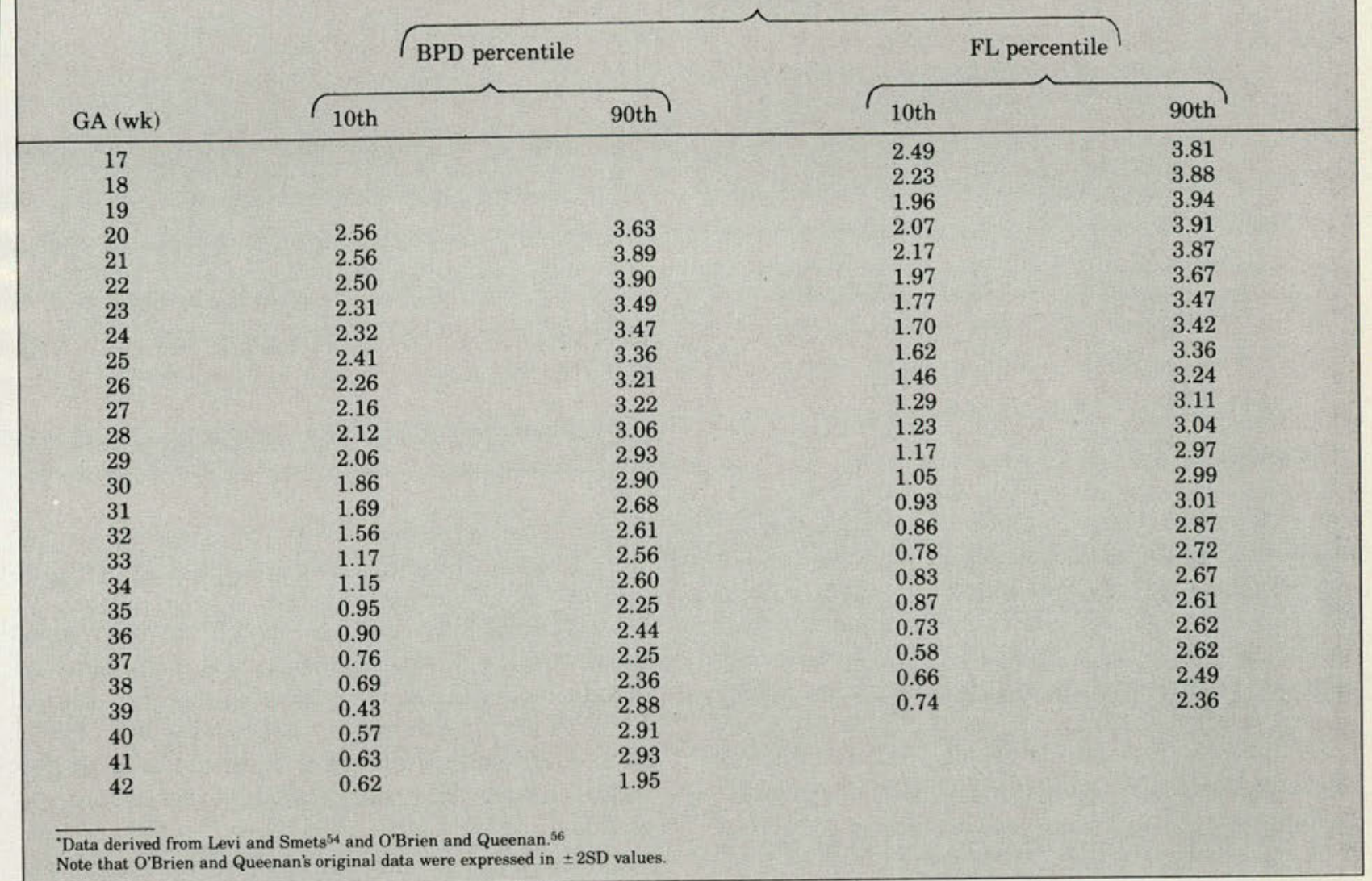

tion that this averaged rate of growth actually occurred at the midpoint between examinations.

Growth rates of other body parts also can be used similarly to detect aberrations of fetal growth. FL growth rate is especially useful in this regard because recognition of decreased femur growth is one of the few ways of detecting the symmetric form of IUGR. Table 6 reflects the data of O'Brien and Queenan ${ }^{56}$ regarding FL growth rates, as based on 620 measurements of 149 patients from 17 to 39 weeks' gestation.

\section{Fetal weight}

Because IUGR and macrosomia are actually defined in terms of weight percentiles, many authors have attempted to find relationships between ultrasonically measured fetal parameters and intrauterine weight. Fetal weight then would be estimated and compared with the normal distribution range for that age. The two main considerations in using this method are, first, defining a normal distribution of intrauterine fetal weight with respect to gestational age and, second, developing reliable techniques of ultrasonic weight estimation.

Most of the "normal" fetal weight curves have been established by means of data acquired from term and preterm deliveries, that is, weight at birth is plotted against gestational age. It can be argued, however, that data obtained from preterm infants may not truly represent the normal population, because being premature in itself is not normal and the same factor(s) that altered their delivery date may have also altered their weight.

Brenner and co-workers, ${ }^{57}$ however, have shown strong evidence to the contrary. With the use of weights obtained at 8 to 20 menstrual weeks from 430 fetuses that had been aborted with prostaglandins, a weight curve was plotted and found to converge precisely with a second weight curve obtained from 30,772 liveborn infants of 21 to 44 weeks' gestation.

On the assumption that these "birthweight" studies are valid, then, the extremely large populationbased study of Williams and associates ${ }^{58}$ will be used as a standard of fetal weight. They compiled data from 2,288,806 infants born in California from 1970 through 1976. Equations 12 and 13 were de srived from their tabular data of the 10th and 90th percentile ranks (male and female averaged) of white, non-Spanish, singleton births by the use of least squares regression analysis from 22 to 40 weeks' gestation. (Weight is expressed in grams; age, in weeks.) 


\section{Formula 12}

10th percentile weight $=180234-32029.6 \mathrm{GA}$

$$
\begin{aligned}
& +2258.8 \mathrm{GA}^{2}-78.948 \mathrm{GA}^{3} \\
& +1.36745 \mathrm{GA}^{4}-9.35832 \\
& \times 10^{-3} \mathrm{GA}^{5}
\end{aligned}
$$

\section{Formula 13}

$$
\begin{aligned}
\text { 90th percentile weight }= & -139888+24482.4 \mathrm{GA} \\
& -1681.93 \mathrm{GA}^{2} \\
& +56.6236 \mathrm{GA}^{3} \\
& -0.928645 \mathrm{GA}^{4} \\
& +5.9487 \times 10^{-3} \mathrm{GA}^{5}
\end{aligned}
$$

Because of the nature of the derivation of equations 12 and 13 , they are not valid outside the 22to 40 -week gestational period.

Many methods of ultrasonic fetal weight prediction have been described. The equations listed in Table $7^{59-61}$ have been chosen for this protocol because of their low standard deviations of correct weight prediction and their use of commonly measured fetal parameters (BPD, HC, AC, and FL). In any given case, the equation with the lowest standard deviation that incorporates all the available fetal parameters will be used to calculate weight.

\section{Qualitative considerations}

Many other ultrasonic findings associated with aberrant fetal growth have been identified. Philipson and coauthors ${ }^{62}$ have shown a fourfold increased incidence of IUGR associated with oligohydramnios, but believe that this finding does not have enough predictive value to be used as a good sole criterion for IUGR. Oligohydramnios has also been shown to be associated with postmaturity. ${ }^{63}$ Polyhydramnios, on the other hand, has been reported as an indicator of macrosomia. ${ }^{64}$

The placental grading system devised by Grannum and coauthors ${ }^{65}$ is not the predictor of fetal maturity it was originally hoped to be; however, there is evidence to show that a grade 3 placenta associated with a fetus weighing $<2,700 \mathrm{~g}$ can be used as an indicator of IUGR. ${ }^{66}$

Thomson and associates ${ }^{67}$ have pointed out the effects of sex, parity, and maternal size on fetal growth and suggest that corrections to the stan-

\begin{tabular}{|c|c|c|c|}
\hline $\begin{array}{l}\text { Ref } \\
\text { no. }\end{array}$ & 2SD & Parameters & Equation \\
\hline 59 & $15.0 \%$ & $\mathrm{HC}, \mathrm{AC}, \mathrm{FL}$ & $\begin{array}{l}\log _{10}(\text { weight })=1.326-0.00326(\mathrm{AC}) \\
\times(\mathrm{FL})+0.0107(\mathrm{HC})+0.0438(\mathrm{AC}) \\
+0.158(\mathrm{FL})\end{array}$ \\
\hline 59 & $15.0 \%$ & $\mathrm{BPD}, \mathrm{AC}, \mathrm{FL}$ & $\begin{array}{l}\log _{10}(\text { weight })=1.335-0.0034(\mathrm{AC}) \times \\
(\mathrm{FL})+0.0316(\mathrm{BPD})+0.0457(\mathrm{AC})+ \\
0.1623(\mathrm{FL})\end{array}$ \\
\hline 59 & $16.0 \%$ & $\mathrm{AC}, \mathrm{FL}$ & $\begin{array}{l}\log _{10} \text { (weight) }=1.304+0.05281(\mathrm{AC}) \\
+0.1938(\mathrm{FL})-0.004(\mathrm{AC}) \times(\mathrm{FL})\end{array}$ \\
\hline 60 & $18.2 \%$ & $\mathrm{HC}, \mathrm{AC}$ & $\begin{array}{l}\log _{10} \text { (weight) }=1.182+0.0273(\mathrm{HC}) \\
+0.07057(\mathrm{AC})-0.00063(\mathrm{AC})^{2} \\
-0.0002184(\mathrm{HC}) \times(\mathrm{AC})\end{array}$ \\
\hline 61 & $19.2 \%$ & $\mathrm{BPD}, \mathrm{AC}$ & $\begin{array}{l}\log _{10}(\text { weight } / 1,000)=1.7492+0.166 \\
(\mathrm{BPD})+0.046(\mathrm{AC})-0.002646(\mathrm{AC}) \times \\
(\mathrm{BPD})\end{array}$ \\
\hline
\end{tabular}
dards be made for each patient accordingly. Gohari et $\mathrm{al}^{68}$ have proposed the use of total intrauterine volume measurement as an indicator of IUGR; however, subsequent studies have been discouraging. ${ }^{69-71}$ This method also requires the use of a static scanner, which most laboratories do not have available.

\section{Multiple gestations}

Growth analysis of multiple gestations is, in principle, similar to that of singletons, although the standards of growth may differ in this population. Twin BPD and AC growth curves have been found to be significantly different from those in singletons, whereas FL growth appears relatively unchanged. ${ }^{72}$ Thus, estimation of age by BPD and AC requires the use of special twin growth charts (that is, those constructed by Grumbach and coworkers, ${ }^{72}$ ) and should be based on the larger of the two twins because of the high incidence of IUGR in multiple gestations. In fact, twin fetuses account for $17 \%$ of all growth-retarded infants,,$^{73}$ and the perinatal mortality rate in multiple births is increased fivefold over that of singleton. ${ }^{58}$

Williams and associates ${ }^{58}$ have established fetal weight curves of multiple gestations; however, it would be wrong to use these as the standard of normal because of the high percentage of growthretarded infants that must have been included in their study. Instead, it would seem logical to use the singleton 10th percentile as the lower weight limit in multiple gestations as well, because a weight reduction caused by such a nutritional deficit that it induced significant perinatal morbidity and mortality in singletons should be associated with similar deleterious effects in multiple gestations. There is also no obvious reason why the equations to estimate fetal weight in Table 7 should not apply to twins.

The data of Erkkola and colleagues ${ }^{74}$ suggest that a $25 \%$ weight difference between two twin fetuses be used as a criterion of IUGR detection, because they found a nearly $20 \%$ risk of perinatal death of one twin when the birthweight discordancy of twins was $25 \%$ or more. Another criterion sug- 


$$
\begin{aligned}
& \text { NAME - JANE DOE I } \\
& \text { DATE - 7/ SO/ } 86 \\
& \text { LMP - UNKNOWN }
\end{aligned}
$$

FETRL GROWTH RNALYSIS PROFILE

O.M.C.P., DEPT. OF RADIOLOGY

$\begin{array}{rlll}\text { MM } & \text { RGE(WKS) } & +-2 S D \text { RANGE } & \text { 2SD(WKS) } \\ -- & -28 & 28.8-31.2 & 1.2 \\ \text { BPD- } 76 & 30 & 27.9-33.1 & 2.6 \\ \text { HC-- } 281 & 30.5 & 27.2-33.2 & 3 \\ \text { RC- }-261 & 30.2 & 27.8-32 & 2.1 \\ \text { FL-- } 57 & 29.9 & 27\end{array}$

BASED ON BPD, HC, RC, FL, RYG AGE $=30.2$ WKS; EDC $=10,6,86$

CEPHALIC. INDEX工 $78.1 \%$ WHICH IS WITHIN ACCEPTRBLE RANGE

LATERAL VENTRICULAR RATIO DOES NOT EXCEED +2SD FOR RGE

FL/AC RATIO IS WITHIN ACCEPTRBLE RANGE

FL/BPD RATIO IS WITHIN RCCEPTABLE RANGE

HC/AC RATIO IS WITHIN RCCEPTABLE RANGE

BPD GROWTH RRTE IS WNL, $=2.8 \mathrm{MM} / W K$; (RANGE $=2.41-3.36$ )

FL GROWTH RRTE IS WNL, $=2.5 \mathrm{MM} / W K$; (RANGE $=1.62-3.36$ )

\section{BASED ON HC, RC, FL, ESTIMATED FETRL WEIOHT = 1533 GMS;}

10 TO $90 \%$ ILE RANGE RT 30.2 WKS $=922$ TO 2085 GMS.

Fig 7. Data entered: Date, 7/30/86; BPD, $76 \mathrm{~mm}$; occipitofrontal diameter (OFD), 100; AP abd diam, 82; transv abd diam, 84; FL, 57; lateral ventricular width, 10; hemispheric width, 36; prior exam date, 5/21/86; prior estimated age, 20 wks; prior BPD, 48; prior $F L, 32$. Computer profile indicates normal growth with estimated gestational age, 30.2 weeks; estimated date of confinement (EDC), $10 / 6 / 86$.

gested by Barnea and colleagues ${ }^{75}$ is a difference of $>20 \mathrm{~mm}$ in $\mathrm{AC}$ between twins. They found a $39 \%$ incidence of IUGR in such twins as opposed to an $8 \%$ incidence in those with $<20 \mathrm{~mm}$ discrepancy.

\section{Computer program}

The following outline represents the general algorithm for the computer program. In addition, however, are many internal checks so that the operator does not make any obvious mistakes while using this program (such as absurd dates, misplaced decimal points, wrong units of measurement). It is also important that the computer checks to make sure that all formulas used are indeed valid for the estimated age of the fetus.

\section{Computer protocol}

(I) Enter all available data into computer:

(A) Patient's name

(B) Date

(C) Last menstrual period date (LMP)

(D) Prior examination?
(1) Date
(2) BPD
(3) $\mathrm{FL}$
(4) Prior estimated age

(E) Current fetal parameters

(1) BPD (outer to inner measurement)

(2) BPD (outer to outer measurement)

(a) If not obtained, estimate based on equation 5 


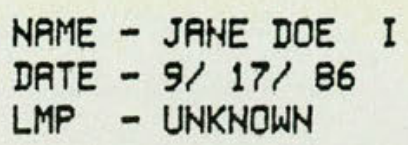

FETAL GROWTH RNALYSIS PROFILE

O.M.C.P., DEPT. OF RADIOLOGY

$\begin{array}{rlll}\text { MM } & \text { RGE(WKS) } & \text { +-2SD RANGE } & \text { 2SD(WKS) } \\ -- & -32.6 & 30.9-34.3 & 1.7 \\ \text { BPD- } 82 & 32.5 & 30.5-36.1 & 2.8 \\ \text { HC- } 383 & 33.3 & 39.5 \\ \text { AC- } 284 & 32.5 & 29.5-35.5 & 3 \\ \text { FL-- 72 } & 36.9 & 33.8-48 & 3.1\end{array}$

BASED ON FL, AVO RGE $=36.9$ WKS; EDC $=10 / 8 / 86$

CEPHALIC INDEX $=77.9 \%$ WHICH IS WITHIN ACCEPTABLE RANGE LRTERAL VENTRICULAR RATIO DOES NOT EXCEED +2SD FOR RGE FL/AC $=.2535$ WHICH IS *OUT* OF ACCEPTABLE RANGE (.205-.235)

FL, 'BPD RATIO IS WITHIN RCCEPTABLE RANGE

HC/AC $=1.067$ WHICH IS *OUT* OF RCCEPTABLE RANGE (.92-1.05) BPD GROWTH RATE (.85? MM/WK) IS *LESS* THAN 10TH \%ILE( $1.15-2.6$ ) FL GROWTH RATE IS WHL, $=2.143$ MM/WK; (RANGE $=.83-2.67$ )

BASED ON HC, AC, FL, ESTIMATED FETAL WEIGHT $=2318$ GMS; 10 TO $90 \%$ ILE RANGE AT 36.9 WKS $=2336$ TO 3614 GMS.

Fig 8. Data entered: Date, 9/17/86; BPD, 82; OFD, 108; AP abd diam, 90; transv abd diam, 91; FL, 72; lat vent width, 11 ; hemispheric width, 41; prior examination date, 7/30/86; prior estimated age, 30.2 wks; prior BPD, 76; prior FL, 57. Same patient as in Fig 7 . Computer growth profile now indicates presence of asymmetric IUGR, FL appears unaffected, while AC shows greatest change. Both $F L / A C$ and $H C / A C$ ratios are abnormally increased. BPD growth rate is decreased. Fetal weight is also decreased from normal range for this age.

(3) Occipitofrontal diameter (OFD)

(4) Calculate $\mathrm{HC}$ (equation 4)

(5) Calculate cephalic index

(6) Calculate circumference-corrected BPD (equation 8)

(7) AP and transverse abdominal diameters

(8) Calculate AC

(9) $\mathrm{FL}$

(10) Lateral ventricular width

(11) Hemispheric width

(II) Calculate age (and SD) based on:

(A) BPD (use circumference correction if possible) using tabular data
(B) HC using equation 6

(C) FL using equation 9

(D) $\mathrm{AC}$ using equation 10

(III) Display for operator:

(A) Ages based on BPD, HC, FL, AC

(B) Age based on LMP

(C) Cephalic index

(D) FL/AC ratio

(IV) On the basis of displayed data, ask which parameters the operator wishes to include in the averaged estimate of gestational age; then obtain by averaging these. 


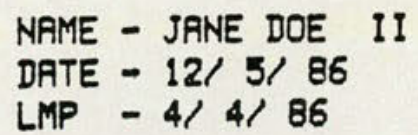

FETRL GROWTH ANALYSIS PROFILE

O.M.C.P., DEPT. OF RADIOLOBY

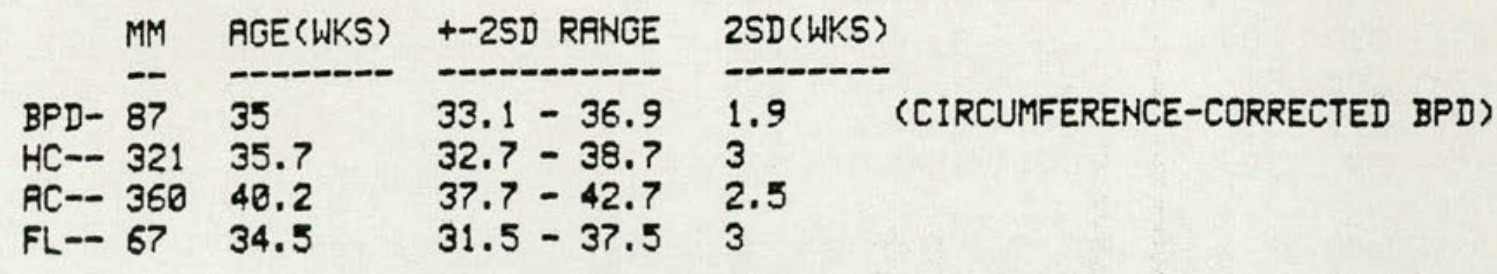

BASED ON BPD, HC, FL, RVG RGE $=35.1$ WKS; EDC $=1 / 8 / 87$

BRSED ON LMP OF $4 / 4 / 86$, RGE $=35$ WKS; EDC $=1 / 9 / 87$

CEPHALIC INDEX $=33.6 \%$ WHICH IS *OUT* OF ACCEPTABLE RANGE (73.9-82.7)

FL/AC $=.1861$ WHICH IS WOUT* OF RCCEPTABLE RANBE (.205-.235)

FL/BPD RATIO IS WITHIN RCCEPTABLE RANGE

HC/AC $=.892$ WHICH IS WOUT* OF ACCEPTABLE RANGE $(.93-1.11$ )

BASED ON HC, RC, FL, ESTIMATED FETRL WEIGHT = 3300 GMS;

10 TO $90 \%$ ILE RANGE RT 35.1 WKS $=1871$ TO 3278 BMS.

Fig 9. Data entered: Date, 12/5/86; LMP, 4/4/86; BPD, 84; OFD, 117; AP abd diam, 112; transv abd diam, 117; FL, 67. No prior exam. Computer profile shows decreased FL/AC and HC/AC ratios as well as abnormally high fetal weight, all of which indicate macrosomia. BPD, HC, and FL measurements correlate well with LMP. Low cephalic index indicates dolichocephaly.

(V) Calculate and display:
(A) Name, date, LMP
(B) Estimated ages based on BPD, HC, AC, and FL
(C) Average estimated age
(D) Estimated date of confinement (EDC) based on average estimated age
(E) EDC based on LMP
(F) Cephalic index
(G) Lateral ventricular ratio (LVR)
(H) FL/AC ratio
(I) $\mathrm{FL} / \mathrm{BPD}$ ratio
(J) $\mathrm{HC} / \mathrm{AC}$ ratio
(K) BPD growth rate
(L) FL growth rate
(M) Estimated fetal weight and normal 10th and

90th percentile range for calculated age (equations 12 and 13; Table 7)

\section{Results of computer trials}

The results and interpretation of a few example trials based on this computer protocol are shown in Figs 7-10. The program was written and tested on a Commodore 64 personal computer using BASIC language and can be applied to almost any other microcomputer with only slight modification.

\section{Comment}

This computerized system of fetal growth analysis has been used at the Osteopathic Medical Center of Philadelphia with much success. In developing this protocol, only the most commonly measured fetal parameters were employed, so that familiar- 


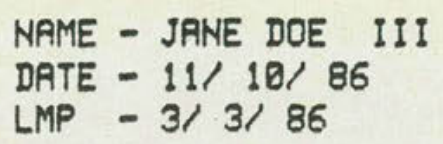

\section{FETAL GROWTH ANALYSIS PROFILE O.M.C.P., DEPT. OF RADIOLOGY}

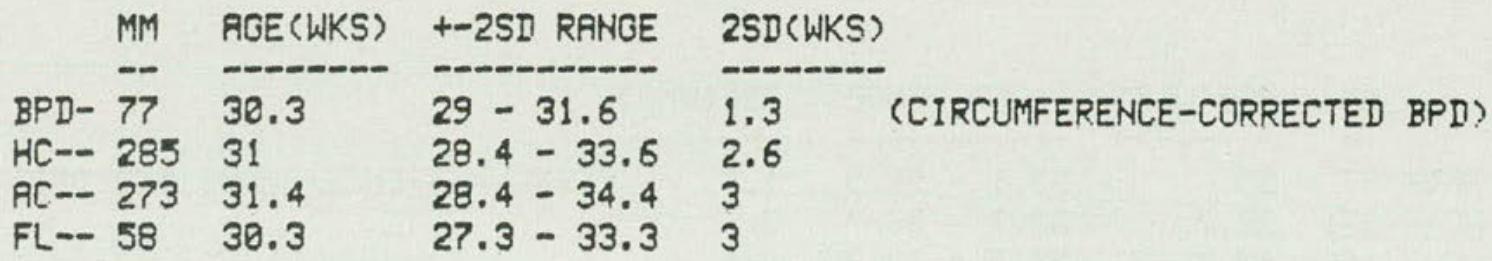

BRSED ON BPD, $H C, R C, F L$, RYG RGE $=30.8$ WKS; EDC $=1 / 13 / 87$

BRSED ON LMP OF $3 / 3 / 86$, RGE $=36$ WKS; EDC $=12 / 8 / 86$

CEPHALIC INDEX $=81.1 \%$ WHICH IS WITHIN ACCEPTABLE RANGE

LATERAL VENTRICULAR RATIO $=38 \%$; WORE* THAN +2SD FOR AGE ( $36 \%)$

FL/AC RATIO IS WITHIN ACCEPTABLE RANGE

FL/BPD RATIO IS WITHIN RCCEPTRBLE RRNGE

HC/AC RATIO IS WITHIN RCCEPTABLE RANGE

BPD GROWTH RATE ( 1.667 MM/WK) IS WLESS* THRN 10TH \%ILE $(2.06-2.93$ )

FL GROWTH RATE ( 1 MM/WK) IS *LESS* THAN 10TH \%ILE( $1.17-2.97$ )

BASED ON HC, AC, FL, ESTIMRTED FETAL WEIGHT = 1686 GMS;

10 TO $90 \%$ ILE RANGE RT 30.8 WKS $=1003$ TO 2237 OMS.

Fig. 10. Data entered: Date, $11 / 10 / 86 ; L M P=3 / 3 / 86 ; B P D=79 ; O F D=100 ; A P$ abd diam $=86 ;$ transv abd diam $=88 ; F L=$ 58 ; lat vent width $=15$; hemispheric width $=40 ;$ prior exam date $=9 / 29 / 86 ;$ prior estimated age $=27.4$ wk; prior BPD $=69 ;$ prior $F L=52$. Computer profile shows decreased BPD and FL growth rates as well as estimated age that does not correspond with LMP Findings are compatible with symmetric IUGR. Increased LVR suggests presence of hydrocephaly.

ity with conventional techniques was preserved. As newer and more accepted information becomes available in the literature, however, continual upgrading of this protocol is in order.

Because gestational sac size and CRL measurements both relate to early pregnancy before growth aberrations become apparent, they are not included in this protocol. The program does not specifically consider twin growth, because only limited information concerning multiple gestations presently is available in the literature. When using this protocol, it should be remembered that the most accurate age estimates, in general, are the earliest, and that age estimates based upon repeat examinations should always be correlated with earlier determinations. This is especially important in symmetric IUGR when the commonly used ratios show no evidence of abnormality. Frequently, some indicators of abnormal growth will be present while other criteria show no abnormality. In these cases the clinician should be alerted to the possibilites, and follow-up examinations may be warranted.

1. Hertz, RH, Sokol RJ, Knoke JD, and associates: Clinical estimation of gestational age: Rules for avoiding preterm delivery. Am J Obstet Gynecol 1978;131:395-402.

2. Wenner WM, Young EB: Nonspecific date of last menstrual period: An indication of poor reproductive outcome. Am J Obstet Gynecol 1974;120:1071-1079. 
3. Seeds, JW: Impaired fetal growth: Definition and clinical diagnosis. Obstet Gynecol 1984;64:303-310.

4. Sanders RC, James AE Jr (eds): The Principles and Practice of Ultrasonography in Obstetrics and Gynecology, ed 3. Norwalk, Conn, AppletonCentury-Crofts, 1985, pp 147-173.

5. Campbell S, Dewhurst CJ: Diagnosis of the small-for-dates fetus by serial ultrasonic cephalometry. Lancet 1971;2:1002-1006.

6. Warsof SL, Cooper DJ, Little D, and associates: Routine ultrasound screening for antenatal detection of intrauterine growth retardation. $\mathrm{Ob}$ stet Gynecol 1986;67:33-39.

7. Little D, Campbell S: Ultrasound evaluation of intrauterine growth retardation. Radiol Clin N Am 1982;20:335-351.

8. Hadlock FP, Deter RL, Harrist RB: Sonographic detection of abnormal fetal growth patterns.Clin Obstet Gynecol 1984;27:342-351.

9. Klebnoff MA, Mills JL, Berendes HW: Mother's birth weight as a predictor of macrosomia. Am J Obstet Gynecol 1985;153:253-257.

10. Spellacy WN, Miller S, Winegar A, and associates: Macrosomiamaternal characteristics and infant complications. Obstet Gynecol 1985;66:158-161.

11. Manara LR: Intrapartum fetal morbidity in intrauterine growthretardation infants. JAOA 1980;80:101-104.

12. Butler NR, Ackerman ED (eds): Perinatal Problems: The Second Report of the 1958 British Perinatal Mortality Survey. Edinburgh, E \& S Livingstone, 1969.

13. Usher RH: Clinical and therapeutic aspects of fetal malnutrition. Pediatr Clin N Am 1970;17:169-183.

14. Usher RH, McLean FH: Normal fetal growth and the significance of fetal growth retardation, in Davis JA, Dobbing H (eds): Scientific Foundations of Pediatrics. London, Heinemann, 1974, p 69.

15. Ogata ES, Sabbagha R, Metzger BE, and associates: Serial ultrasonography to assess evolving fetal macrosomia: Studies in 23 pregnant diabetic women. JAMA 1980;243:2405-2408.

16. Elliott JP, Garite TJ, Freeman RK, and associates: Ultrasonic prediction of fetal macrosomia in diabetic patients. Obstet Gynecol 1982;60:159-162.

17. Cooperberg PL, Chow T, Kite, V, and associates: Biparietal diameter: A comparison of real time and conventional B-scan techniques. JCU $1976 ; 4: 421-423$

18. Lawson TL, Albarelli JN, Greenhouse SW, and associates: Gray scale measurement of biparietal diameter. JCU 1977;5:17-20.

19. Docker MF, Settattree RS: Comparison between linear array real time ultrasonic scanning and conventional compound scanning in the measurement of the fetal biparietal diameter. $\mathrm{Br} J$ Obstet Gynaecol $1977 ; 84: 924-929$

20. Robinson HP, Fleming JEE: A critical evaluation of sonar "crownrump length" measurements. Br J Obstet Gynecol 1975;82:702-710.

21. Campbell S, Warsof SL, Little D, and associates: Routine ultrasound screening for the prediction of gestational age. Obstet Gynecol 1985;65:613. 620 .

22. Hellman LM, Kobayashi M, Fillisti L, and associates: Growth and development of the human fetus prior to the twentieth week of gestation.Am J Obstet Gynecol 1969;103:789-800.

23. American College of Obstetricians and Gynecologists Technical Bulletin no. 63,1981 .

24. Shepard M, Filly RA: A standardized plane for biparietal diameter measurement. $J$ Ultrasound Med 1982;1:145-150.

25. Hadlock FP, Deter RL, Harrist RB, and associates: Fetal biparietal diameter: Rational choice of plane of section for sonographic measurement. AJR 1982;138:871-874

26. Kurtz AB, Wapner RJ, Kurtz RJ, and associates: Analysis of biparietal diameter as an accurate indicator of gestational age. JCU 1980;8:319. 326.

27. Selbing A, Kjessler B: Conceptual dating by ultrasonic measurement of the fetal biparietal diameter in early pregnancy. Acta Obstet Gynecol Scand 1985;64:593-597.

28. Hadlock FP, Deter RL, Carpenter RJ, and associates: Estimating fetal age: Effect of head shape on BPD. AJR 1981;137:83-85.

29. Hadlock FP, Kent WR, Loyd JL, and associates: An evaluation of two methods for measuring fetal head and body circumference. $J$ Ultrasound Med 1982;1:359-360.

30. DeVore GR, Platt LD: Choosing the correct equation for computing the head circumference from two diameters: The effect of head shape. Am J Obstet Gynecol 1984;148:221-222.

31. Souder M (ed): Handbook of Engineering Fundamentals, ed 3. New York, John Wiley \& Sons, Inc., 1976.
32. Doubilet PM, Greenes RA: Improved prediction of gestational age from fetal head measurements. AJR 1984;142:797-800.

33. Hadlock FP, Deter RL, Harrist RB and associates: Fetal head circumference: Relation to menstrual age. AJR 1982;138:649-653.

34. Hadlock FP, Harrist RB, Deter RL, and associates: Fetal femur length as a predictor of menstrual age: Sonographically measured. AJR 1982;138:875-878.

35. Hadlock FP, Harrist RB, Deter RL, and associates: A prospective evaluation of fetal femur length as a predictor of gestational age. $J U l$. trasound Med 1983;2:111-112.

36. Jeanty P, Rodesch F, Delbeke D, and associates: Estimation of gestational age from measurements of fetal long bones. $J$ Ultrasound Med 1984;3:75-79.

37. Hadlock FP, Deter RL, Harrist RB, and associates: Estimating fetal age: Computer-assisted analysis of multiple fetal growth parameters. Radiology 1984;152:497-501.

38. Shalev E, Feldman E, Weiner E, and associates: Assessment of gestational age by ultrasonic measurement of the femur length. Acta $\mathrm{Ob}$ stet Gynecol Scand 1985;64:71-74

39. Hohler CW, Quetel TA: Comparison of ultrasound femur length and biparietal diameter in late pregnancy. Am J Obstet Gynecol 1981;141:759762

40. O'Brien GD, Queenan JT: Ultrasound fetal femur length in relation to intrauterine growth retardation: Part 2. Am J Obstet Gynecol 1982;144:35-59.

41. Hadlock FP, Deter RL, Harrist RB, and associates: A date-independent predictor of intrauterine growth retardation: Femur length/abdominal circumference ratio. AJR 1983;141:979-984.

42. Hadlock FP, Harrist RB, Fearneyhough TC, and associates: Use of femur length/abdominal circumference ratio in detecting the macrosomic fetus. Radiology 1985;154:503-505.

43. Ott WJ: Fetal femur length, neonatal crown-heel length, and screening for intrauterine growth retardation. Obstet Gynecol 1985;65:460464 .

44. Hadlock FP, Deter RL, Roecker E, and associates: Relation of fetal femur length to neonatal crown-heel length. J Ultrasound Med 1984;3:13.

45. Campbell S, Thoms A: Ultrasound measurement of the fetal head to abdomen circumference ratio in the assessment of growth retardation. Br J Obstet Gynecol 1977;84:165-174

46. Crane JP, Kopta MM: Prediction of intrauterine growth retardation via ultrasonically measured head/abdominal circumference ratios. $\mathrm{Ob}$ stet Gynecol 1979;54:597-601.

47. Tamura RK, Sabbagha RE: Percentile ranks of sonar fetal abdominal circumference measurements. Am J Obstet Gynecol 1980;138:475479 .

48. Duff GB, Evans LJ: Measurement of the fetal biparietal diameter by ultrasound is not an accurate method of detecting fetal growth retardation. NZ Med J 1981;94:312-314.

49. Deter RL, Harrist RB, Hadlock FP, and associates: Longitudinal studies of fetal growth with the use of dynamic image ultrasonography. Am J Obstet Gynecol 1982;143:545-554.

50. Hadlock FP, Deter RL, Harrist RB, and associates: Fetal abdominal circumference as a predictor of menstrual age. AJR 1982;139:367-370. 51. Johnson ML, Dunne, MG, Mack LA, and associates: Evaluation of fetal intracranial anatomy by static and real-time ultrasound. JCU 1980;8:311-318.

52. Pretorius DH, Drose JA, Manco-Johnson ML: Fetal lateral ventricular ratio determination during the second trimester. $J$ Ultrasound Med 1986;5:121-124.

53. Campbell S, Newman GB: Growth of the fetal biparietal diameter during normal pregnancy. $J$ Obstet Gynecol Br Commonw 1971;78:513519.

54. Levi S, Smets P: Intra-uterine fetal growth studied by ultrasonic biparietal measurements: The percentiles of biparietal distribution. Acta Obstet Gynecol Scand 1973;52:193-198.

55. Sholl JS, Woo D, Rubin JM, and associates: Intrauterine growth retardation risk detection for fetuses of unknown gestational age. Am J Obstet Gynecol 1982;144:709-714.

56. O'Brien GD, Queenan JT: Growth of the ultrasound fetal femur length during normal pregnancy: Part I. Am J Obstet Gynecol 1981;141:833837

57. Brenner WE, Edelman DA, Hendricks $\mathrm{CH}$ : A standard of fetal growth for the United States of America. Am J Obstet Gynecol 1976;126:555564.

58. Williams RL, Creasy RK, Cunningham GC, et al: Fetal growth and 
perinatal viability in California. Obstet Gynecol 1982;59:624-632

59. Hadlock FP, Harrist RB, Sharman RS, et al: Estimation of fetal weight with the use of head, body, and femur measurements - a prospective study. Am J Obstet Gynecol 1985;151:222-337.

60. Hadlock FP, Harrist RB, Carpenter RJ, and associates: Sonographic estimation of fetal weight. Radiology 1984;150:535-540.

61. Shepard MJ, Richards VA, Berkowitz RL, and associates: An evaluation of two equations for predicting fetal weight by ultrasound. $A m J$ Obstet Gynecol 1982;142:47-54.

62. Philipson EH, Sokol RJ, Williams T: Oliogohydramnios: Clinical associations and predictive value for intrauterine growth retardation. Am $J$ Obstet Gynecol 1983;146:271-278.

63. Moya F, Grannum P, Pinto K, and associates: Ultrasound assess ment of the postmature pregnancy. Obstet Gynecol 1985;65:319-322.

64. Chamberlain PF, Manning FA, Morrison I, and associates: Ultrasound evaluation of amniotic fluid volume: II. The relationship of increased amniotic fluid volume to perinatal outcome. Am J Obstet Gynecol 1984;150:250-254.

65. Grannum PAT, Berkowitz RL, Hobbins JC: The ultrasonic changes in the maturing placenta and their relation to fetal pulmonic maturity. Am J Obstet Gynecol 1979;133:915-922.

66. Kazzi GM, Gross TL, Sokol RJ, and associates: Detection of intrauterine growth retardation: A new use for sonographic placental grading. Am J Obstet Gynecol 1983;145:733-738.

67. Thomson AM, Billewicz WZ, Hytten FE: The assessment of fetal growth. J Obstet Gynecol Br Commonw 1968;75:903-916.

68. Gohari P, Berkowitz RL, Hobbins JC: Prediction of intrauterine growth retardation by determination of total intrauterine volume. $\mathrm{Am}$ J Obstet Gynecol 1977;127:255-260.
69. Grossman M, Flynn JJ, Aufrichtig D, et al: Pitfalls in ultrasonic determination of total intrauterine volume. JCU 1982;10:17-20.

70. Warsof SL, Gohari P, Berkowitz RL, and associates: The estimation of fetal weight by computer-assisted analysis. Am J Obstet Gynecol 1977; 128:881-892.

71. Chinn DH, Filly RA, Callen PW: Prediction of intrauterine growth retardation by sonographc estimation of total intrauterine volume. JCU $1981 ; 9: 175-179$

72. Grumbach K, Coleman BG, Arger PH, and associates: Twin and singleton growth patterns compared using US. Radiology 1986;158:237. 241.

73. Manlan G, Scott KE; Contribution of twin pregnancy to perinatal mortality and fetal growth retardation: Reversal of growth retardation after birth. Can Med Assoc J 1978;118:365-368.

74. Erkkola R, Ala-Mello S, Piiroinen O, and associates: Growth discordancy in twin pregnancies: A risk factor not detected by measurements of biparietal diameter. Obstet Gynecol 1985;66:203-206.

75. Barnea ER, Romero R, Scott D, and associates: The value of biparietal diameter and abdiominal perimeter in the diagnosis of growth retardation in twin gestation. Am J Perinatol 1985;2:221-222.

From the Department of Radiology, Osteopathic Medical Center of Philadelphia.

Reprint requests to Dr Stankiewicz, 623 Lang Ave, Patton PA 16668 . 


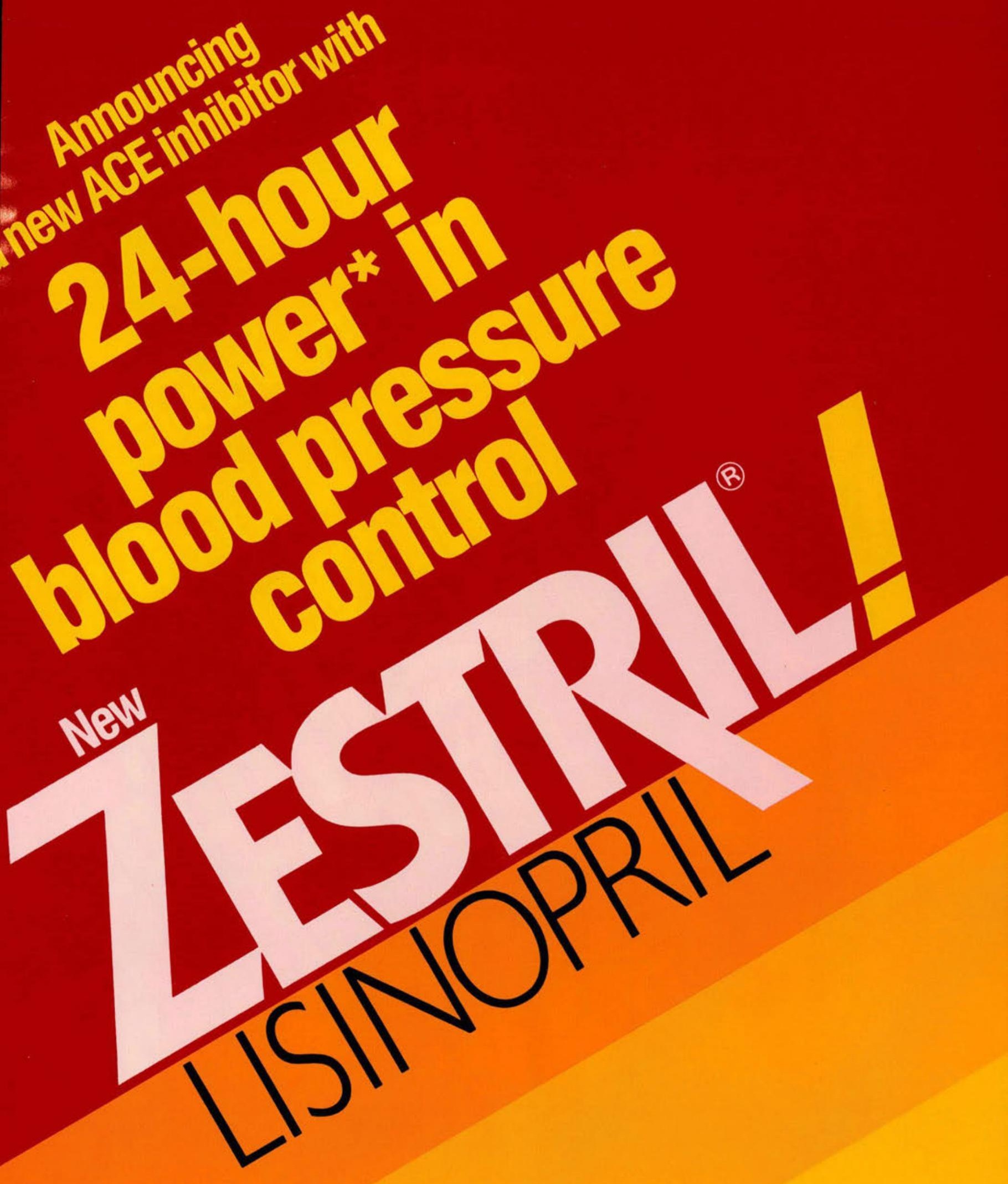

The antihypertensive effect may diminish at the end of the dosing interval.

Pease see last page of this advertisement for brief summary of prescribing information. 


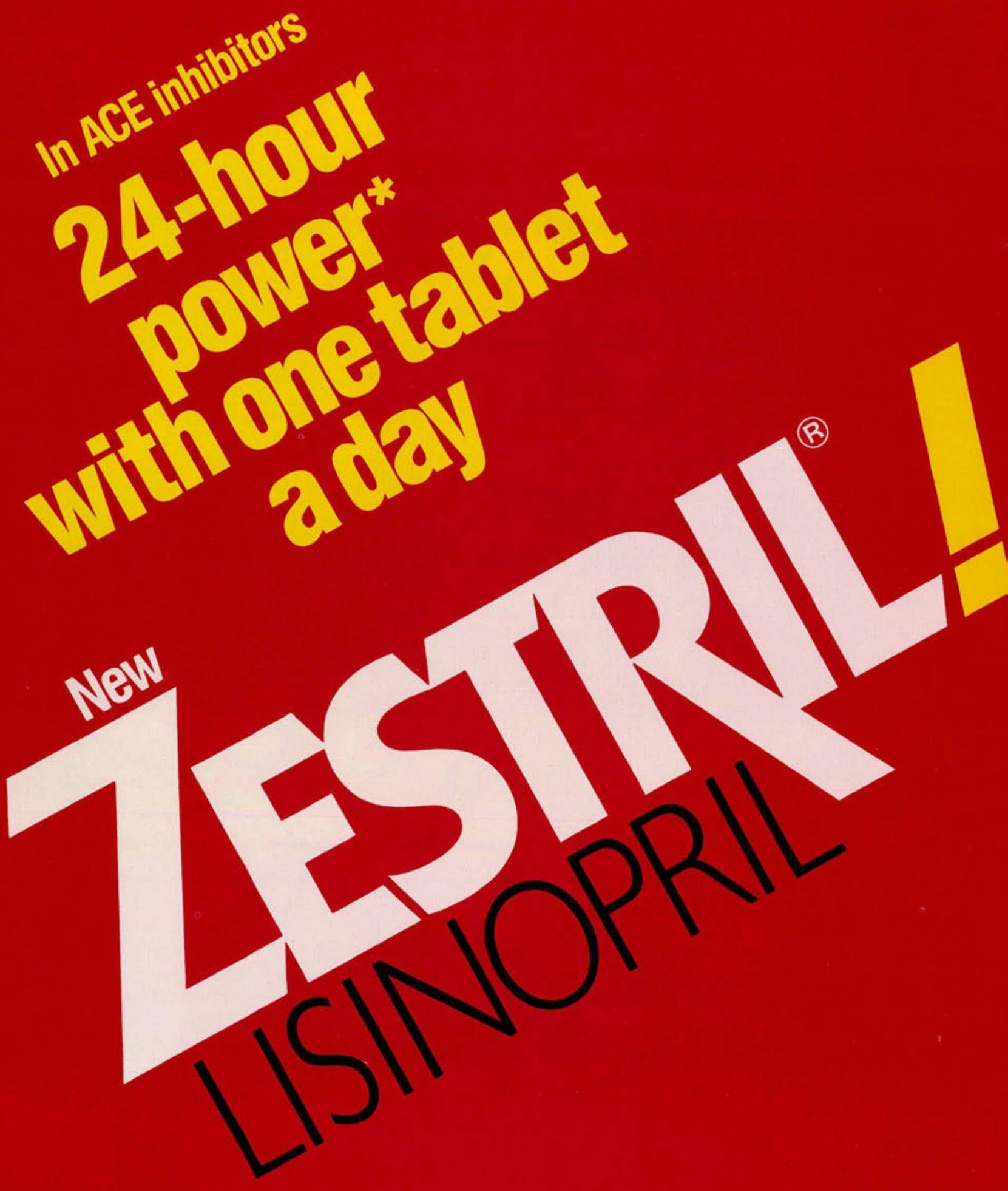

\section{Zestril: The long-acting ACE inhibitor}

Zestril achieves 24-hour blood pressure control with a half-life of 12 hours.' Angiotensin converting enzyme (ACE) inhibition t is long lasting with Zestrilsustained 24 hours after a single dose. ${ }^{2.4}$ The clinical significance of pharmacodynamic differences among ACE inhibitors in hypertensive patients has not been determined. 


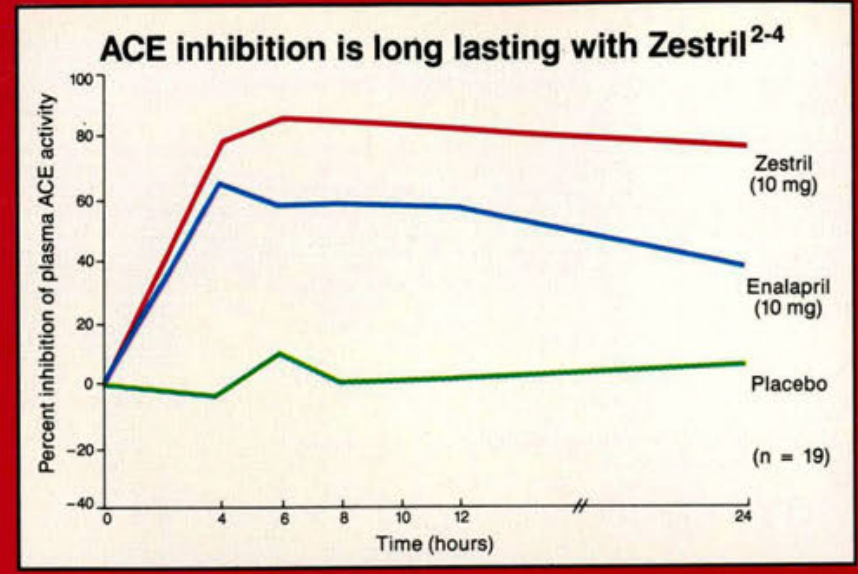

${ }^{\dagger}$ In pharmacodynamic studies (utilizing $10 \mathrm{mg}$ of enalapril and lisinopril), ACE inhibition was significantly correlated to plasma renin activity and fall in diastolic blood pressure in normal volunteers.

- adapted from Ajayi et al, p $424^{2}$

\section{Zestril: Hypertensive patients start and stay at one tablet a day}

A single tablet of Zestril reduces blood pressure for 24 hours ${ }^{1}$ - unlike other ACE inhibitors, which may have to be increased to b.i.d. ${ }^{5}$ or t.i.d. ${ }^{6}$ dosing in some patients. The predictable once-daily dosage of Zestril enhances patient compliance and cost-effectiveness.

\section{Zestril: 24-hour blood pressure control that's easy to live with}

Zestril shares the low incidence of side effects characteristic of ACE inhibitors. Additionally, rash or taste disturbance are rarely seen with Zestril. What's more, Zestril is not metabolized by the liver. It is absorbed as the active drug and does not require bioactivation ${ }^{7}-$ as needed with prodrugs such as enalapril..5,7 Absorption of Zestril is unaffected by food. ${ }^{8}$

Evaluation of the hypertensive patient should always include assessment of renal function. (See Dosage and Administration.)

Angioedema has been reported with ACE inhibitors, including Zestril. (See Warnings.)

1988 ICI Americas Inc

le antihypertensive effect may diminish at the end the dosing interval.

inical significance has not been determined in pertensive patients. 
ZESTRIL* (lisinoprii)

INDICATIONS AND USAGE. Zestril is indicated for the treatment of hypertension. It may be used alone as initial therapy or concomitantly with other classes of antihypertensive agents. In using Zestril, consideration should be given to the fact that another angiotensin converting enzyme inhibitor, captoprii, has caused data are insufficient to show that Zestril does not have a similar risk. (See WARNINGS.) CONTRAINDICATIONS. Zestril is contraindicated in patients who are hypersensitive to this product. WARNINGS. Angioedema: Angioedema of the face, extremities, lips, tongue, glottis and/or larynx has been reported in patients treated with angiotensin converting enzyme inhibitors, including Zestriil. In such cases, Zestril should be promptly discontinued, and the patient carefully observed until the swelling disappears. In instances where swellin antihistamines have been useful in relieving symptoms. Angioedema associated with laryngeal edema may

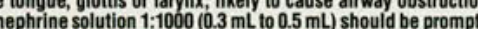
appropriate therapy, eg, subcutaneous epinephrine solution 1:1000 (3. plicated hypertensive patients but is a possible consequence of use with Zestril in salt/volume-depleted persons, SUCh as those treated vigorously with diuretics or patients on dialysis. (See PRECAUTIONS, Drug Interactions insufficiency, excessive hypotension has been observed and may be associated with oliguria and/or progressive azotemia, and rarely with acute renal failure and/or death. Because of the potential fall in blood pressure followed closely for the first two weeks of treatment and whenever the dose of Zestril and/or diuretic is increased. Similar considerations apply to patients with ischemic heart or cerebrovascular disease in whom an excessive tali in blood pressure could result in a myocardial infarction or cerebrovascular accident. If hypotension occurs. saline. A transient hypotensive response is not a contraindication to further doses which usually can be given without difficulty once the blood pressure has increased after volume expansion. Neutropenia/Agranulocytosis: Another angiotensin converting enzyme inhibitor, captopril, has been shown to cause agranulocytosis and bone marrow depression, rarely in uncomplicated patients but more frequently in patients with renal impairmen especially if they also have a collagen vascular disease. Available data from clinical trials of Zestril are insufficient
to show that Zestril does not cause agranulocytosis at similar rates. Periodic monitoring of white blood cel counts in patients with collagen vascular disease and renal disease should be considered. PRECAUTIONS General. Impaired Renal Function: As a consequence of inhibiting the renin-angiotensin-aldosterone system, changes in renal function may be anticipated in susceptible individuals. In patients with severe congestive treatment with angiotensin converting enzyme inhibitors, including Zestril, may be associated with oliguria treatment with angiotensin converting enzyme inhibitors, including Zestril, may be associated with oliguria
and/or progressive azotemia and rarely with acute renal failure and/or death. In hypertensive patients with and/or progressive azotemia and rarely with acute renal failure and/or death. In hypertensive patients with
unilateral or bilateral renal artery stenosis, increases in blood urea nitrogen and serum creatinine may occur unilateral or bilateral renal artery stenosis, increases in blood urea nitrogen and serum creatinine may occur.
Experience with another angiotensin converting enzyme inhibitor suggests that these increases are usually Experience with another angiotensin converting enzyme inhibitor suggests that these increases are usually
reversible upon discontinuation of Zestril and/or diuretic therapy. In such patients, renal function should be reversible upon discontinuation of Zestril and/or diuretic therapy. In such patients, renal function should be
monitored during the first few weeks of therapy. Some hypertensive patients with no apparent pre-existing monitored during the first few weeks of therapy. Some hypertensive patients with no apparent pre-existing
renal vascular disease have developed increases in blood urea nitrogen and serum creatinine, usually minor and transient, especially when Zestril has been given concomitantly with a diuretic. This is more likely to cccur in patients with pre-existing renal impairment. Dosage reduction of 7 estril and/or discontinuation the diuretic may be required. Evaluation of the hypertensive patient should always include assessment of renal function. (See DOSAGE AND ADMINISTRATION.) Hyperkalemia: In clinical trials hyperkalemia (serum renal function. (See DOSAGE AND ADMINISTRATION.) Hyperkalemia: In clinical trials hyperkalemia (serum
potassium greater than $5.7 \mathrm{mEq} / \mathrm{L}$ ) Occurred in approximately $2.2 \%$ of hypertensive patients and $4.0 \%$ of potassium greater than $5.7 \mathrm{mEG} / \mathrm{L}$ ) OCcurred in approximately $2.2 \%$ of hypertensive patients and $4.0 \%$ of
patients with congestive heart failure. In most cases these were isolated values which resolved despite continued patients with congestive heart failure. In most cases these were isolated values which resolved despite continued Risk factors for the development of hyperkalemia include renal insufficiency, diabetes mellitus, and the concomitant use of potassium-sparing diuretics, potassium supplements and/or potassium-containing sa In patients undergoing major surgery or during anesthesia with agents that produce hypotension, Zestril may In patients undergoing major surgery or during anesthesia with agents that produce hypotension, Zestril may sidered to be due to this mechanism, it can be corrected by volume expansion. Information for Patients. Angioedema: Angioedema, including laryngeal edema, may occur especially following the first dose of Zestril. Patients should be so advised and told to report immediately any signs or symptoms suggesting angioedema
(swelling of face, extremities, eyes, lips, tongue difficulty in swallowing or breathing) and to take no more (swelling of face, extremities, eyes, lips, tongue, difficulty in swallowing or breathing) and to take no more drug until they have consulted with the prescribing physician. Symptomatic Hypotension: Patients should be cautioned to report lightheadedness especially during the first lew days of therapy. If actual syncope occurs, All patients should be cautioned that excessive perspiration and dehydration may lead to an excessive fall All patients should be cautioned that excessive perspiration and dehydration may lead to an excessive fall or diarrhea may also lead to a fall in blood pressure; patients should be advised to consult with their physician or diarrhea may also lead to a lallin blood pressure, patients should be advised to consult with their physician. Hyperkalemia: Patients should be told not to use salt substitutes containing potassium without consulting their physician. Neutropenia: Patients should be told to report promptly any indication of infection (eg, sore
throat, fever) which may be a sign of neutropenia. NOTE: As with many other drugs, certain advice to patients being treated with Zestril is warranted. This information is intended to aid in the safe and effective use of this medication. It is not a disclosure of all possible adverse or intended effects. Drug Interactions. Hypotension - Patients on Diuretic Therapy: Patients on diuretics and especially those in whom diuretic therapy was recently instituted, may occasionally experience an excessive reduction of blood pressure after initiation of therapy with Zestril. The possibility of hypotensive effects with Zestril can be minimized by either discontinuing the diuretic or increasing the salt intake prior to initiation of treatment with Zestril. If it is necessary to continue the diuretic, initiate therapy with Zestril at a dose of $5 \mathrm{mg}$ daily, and provide medical supervision after the initial dose for at least two hours and until blood pressure has stabilized for at least an additional hour. (See
WARNINGS, and DOSAGE AND ADMINISTRATION.) When a diuretic is added to the therapy of a patient receiving Zestril, an additional antihypertensive effect is usually observed. Studies with ACE inhibitors in combination with diuretics indicate that the dose of the ACE inhibitor can be reduced when it is given with a diuretic. (See DOSAGE AND ADMINISTRATION.) Indomethacin: In a study in 36 patients with mild to moderate hypertension where the antihypertensive effects of Zestril alone were compared to Zestril given concomitantly with indomethacin, the use of indomethacin was associated with a reduced effect, although the difference between the two regimens was not significant. Other Agents: Zestril has been used concomitantly with nitrates and/or digoxin without evidence of clinically significant adverse interactions. No clinically important pharmacokinetic interactions occurred when Zestril was used concomitantly with propranolol or hydrochlorothiazide. The Zestril attenuates potassium loss caused by thiazide-type diuretics. Use of Zestril with potassium-sparing diuretics (eg. spironolactone, triamterene or amiloride), potassium supplements, or potassium-containing salt substitutes may lead to significant increases in serum potassium. Therefore, if concomitant use of these agents is indicated because of demonstrated hypokalemia, they should be used with caution and with frequen of a tumorigenic effect when lisinopril was administered for 105 weeks to male and female rats at doses up to $90 \mathrm{mg} / \mathrm{kg} /$ day (about 56 times" the maximum recommended daily human dose) or when lisinopril was administered for 92 weeks to (male and female) mice at doses up to $135 \mathrm{mg} / \mathrm{kg} / \mathrm{day}$ (about 84 times* the maximum recommended daily human dose). " Based on patient weight of $50 \mathrm{Kg}$. Lisinopril was not mutagenic in the Ames microbial mutagen test with or without metabolic activation. It was also negative in a forward mutation assay using Chinese hamster lung cells. Lisinopril did not produce single strand DNA breaks in an in vitro alkaline elution rat hepatocyte assay. In addition, lisinopril did not produce increases in chromosoma aberrations in an in vitro test in Chinese hamster ovary cells or in an in vivo study in mouse bone marrow. There were no adverse effects on reproductive performance in male and female rats treated with up to $300 \mathrm{mg} / \mathrm{kg} /$ day of lisinopril. Pregnancy. Pregnancy Category C: Lisinopril was not teratogenic in mice treated There was an increase in fetal resorptions at doses down to $100 \mathrm{mg} / \mathrm{kg}$; at doses of 1.000 mg/kg this was prevented by saline supplementation. There was no fetotoxicity or teratogenicity in rats treated with up to $300 \mathrm{mg} / \mathrm{kg} / \mathrm{day}$ ( 188 times the maximum recommended dose) of lisinopril at days $6-17$ of gestation. In rats receiving lisinopril from day 15 of gestation through day 21 postpartum, there was an increased incidence in pup deaths on days $2-7$ postpartum and a lower average body weight of pups on day 21 postpartum. The increase in pup deaths and decrease in pup weight did not occur with maternal saline supplementation in saline supplemented rabbits. Saline supplementation (physiologic saline in place of tap water) was used to eliminate maternotoxic effects and enable evaluation of the teratogenic potential at the highest possible dosage level. The rabbit has been shown to be extremely sensitive to angiotensin converting enzyme inhibitors dosage levels in man. Fetotoxicity was demonstrated in rabbits by an increased incidence of fetal resorptions at a dose of lisinopril at $1 \mathrm{mg} / \mathrm{kg} /$ day and by an increased incidence of incomplete ossification at the lowest dose tested ( $0.1 \mathrm{mg} / \mathrm{kg} / \mathrm{day}$ ). By whole body autoradiography, radioactivity was found in the placenta following administration of labeled lisinopril to pregnant rats, but none was found in the fetuses. There are no adequate and well-controlled studies in pregnant women. Zestril should be used during pregnancy only if the potentia following administrationtial risk to the fetus. Nursing mothers. ${ }^{4} \mathrm{C}$ lisinopril. It is not known whether this drug is excreted in human milk
ZESTRIL" (lisinopril)

Because many drugs are excreted in human milk, caution should be exercised when Zestril is given to an
mother. Pediatric Use: Safety and effectiveness in children have not been established. ADVERSE REACT Zestril has been found to be generally well tolerated in controlled clinical trials involving 2003 patien subjects. The most frequent clinical adverse experiences in controlled trials were dizziness $(6.3 \%)$, hea
$(5.3 \%)$, fatigue $(33 \%)$, diarrhea $(3.2 \%)$, upper respiratory symptoms $(3.0 \%)$, and cough (29\%), all of were more frequent than in placebo-treated patients. For the most part, adverse experiences were mi transient in nature. Discontinuation of therapy was required in $6.0 \%$ of patients. In clinical trials, the
frequency of adverse experiences could not be related to total daily dosage within the recommended thera dosage range. For adverse experiences which occurred in more than $1 \%$ of patients and subjects tr with Zestril or Zestril plus hydrochlorothiazide in controlled clinical trials,

\begin{tabular}{|lccc|}
\hline & $\begin{array}{c}\text { Zestril } \\
(n=2003 \dagger) \\
\text { Incidence } \\
\text { (discontinuation) }\end{array}$ & $\begin{array}{c}\text { Zestril/Hydrochlorothiazide } \\
\left(\begin{array}{l}n=644) \\
\text { Incidence } \\
\text { (discontinuation) }\end{array}\right.\end{array}$ & $\begin{array}{c}\text { Placebo } \\
(n=207) \\
\text { Incidence }\end{array}$ \\
\hline Dizziness & $6.3(0.6)$ & $9.0(0.9)$ & 1.9 \\
Headache & $5.3(0.2)$ & $4.3(0.5)$ & 1.9 \\
Fatigue & $3.3(0.2)$ & $3.9(0.5)$ & 1.0 \\
Diarmea & $3.2(0.3)$ & $2.6(0.3)$ & 2.4 \\
Upper Respiratory Symptoms & $3.0(0.0)$ & $4.5(0.0)$ & 0.0 \\
Cough & $2.9(0.4)$ & $4.5(0.8)$ & 1.0 \\
Nausea & $2.3(0.3)$ & $2.5(0.2)$ & 2.4 \\
Hypotension & $1.8(0.8)$ & $1.6(0.5)$ & 0.5 \\
Rash & $1.5(0.4)$ & $1.6(0.2)$ & 0.5 \\
Orthostatic Effects & $1.4(0.0)$ & $3.4(0.2)$ & 1.0 \\
Asthenia & $1.3(0.4)$ & $2.0(0.2)$ & 1.0 \\
Chest Pain & $1.3(0.1)$ & $1.2(0.2)$ & 1.4 \\
Vomiting & $1.3(0.2)$ & $1.4(0.0)$ & 0.5 \\
Dyspnea & $1.1(0.0)$ & $0.5(0.2)$ & 1.4 \\
Dyspepsia & $1.0(0.0)$ & $1.9(0.0)$ & 0.0 \\
Paresthesia & $0.8(0.0)$ & $2.0(0.2)$ & 0.0 \\
Impotence & $0.7(0.2)$ & $1.6(0.3)$ & 0.0 \\
Muscle Cramps & $0.6(0.0)$ & $2.8(0.6)$ & 0.5 \\
Back Pain & $0.5(0.0)$ & $1.1(0.0)$ & 1.4 \\
Nasal Congestion & $0.3(0.0)$ & $1.2(0.0)$ & 0.0 \\
Decreased Libido & $0.2(0.1)$ & $1.2(0.0)$ & 0.0 \\
Vertigo & $0.1(0.0)$ & $1.1(0.2)$ & 0.0 \\
\hline
\end{tabular}

fincludes 420 patient
diuretic therapy.

Clinical adverse experiences occurring in $0.3 \%$ to $1.0 \%$ of patients in the controlled trials and rarer. ser possibly drug related events reported in uncontrolled studies or marketing experience included: $B O D$ rhythm disturbances, tachycardia, peripheral edema, palpitation. DIGESTIVE: Abdominal pain anorexia stipation, flatulence. METABOLISM: Gout. MUSCULOSKELETAL: Joint pain, shoulder pain. NERVOUS

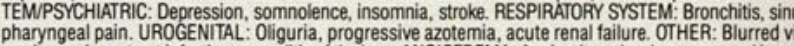
pruritus, urinary tract infection, vasculitis of the legs. ANGIOEDEMA: Angioedema has been reported in pa feceiving Zestril (0.19\%). Angioedema associated with laryngeal edema may be fatal, if angioedema and appropriate therapy instituted immediately. (See WARNINGS.) HYPOTENSION: In hypertensive pati hypotension occurred in $1.2 \%$ and syncope occurred in $0.1 \%$ of patients. Hypotension or syncope
cause of discontinuation of therapy in $0.5 \%$ of hypertensive patients. (See WARNINGS.) In patients congestive heart failure, hypotension occurred in $5.0 \%$ and syncope occurred in $1.0 \%$ of patients. T adverse experiences were causes for discontinuation of therapy in 1.3\% of these patients. Clinical Labor
Test Findings. Serum Electrolytes: Hyperkalemia (See PRECAUTIONS.) Creatinine, Blood Urea Nitro Minor increases in blactrolytes. Hypernalemia (See PRECAUTrins.) Creatinine, blood Urea Nitro observed in about $2.0 \%$ of patients with essential hypertension treated with Zestril alone. Increases more common in patients receiving concomitant diuretics and in patients with renal artery stenosis. PRECAUTIONS.) Reversible minor increases in blood urea nitrogen and serum creatinine were observ 管 Small decreases in hemoglobin and hematocrit (mean decreases of approximately $0.4 \mathrm{~g} \%$ and $1.3 \mathrm{v}$ respectively) occurred frequently in patients treated with Zestril but were rarely of clinical importance in pat without some other cause of anemia. In clinical trials, less than $0.1 \%$ of patients discontinued therap 0 anemia. Other (Causal Relationship Unknown): Rarely, elevations of liver enzymes and/or serum bili have occurred. Overall, $2.0 \%$ of patients discontinued therapy due to laboratory adverse experiences, princi
elevations in blood urea nitrogen $(0.6 \%)$, serum creatinine $(0.5 \%)$, and serum potassium $(0.4 \%)$. OVERDOS The oral $L D_{50}$ of lisinopril is greater than $20 \mathrm{~g} / \mathrm{kg}$ in mice and rats. The most likely manifestation of
ing dosage would be hypotension, for which the usual treatment would be intravenous infusion of normal SOlution. DOSAGE AND ADMINISTRATION. Initial Therapy: In patients with uncomplicated essential tension not on diuretic therapy, the recommended initial dose is $10 \mathrm{mg}$ once a day. Dosage should be adju
according to blood pressure response. The usual dosage range is $20-40 \mathrm{mg}$ per day administered in as according to blood pressure response. The usual dosage range is $20-40 \mathrm{mg}$ per day administered in as
daily dose. The antihypertensive effect may diminish toward the end of the dosing interval regardless daily dose. The antihypertensive effect may diminish toward the end of the dosing interval regardless
administered dose, but most commonly with a dose of $10 \mathrm{mg}$ daily. This can be evaluated by measuring pressure just prior to dosing to determine whether satisfactory control is being maintained for 24 hou an increase in dose should be considered. Doses up to $80 \mathrm{mg}$ have been used but do not ap to give greater effect. If blood pressure is not controlled with Zestril alone, a low dose of a diuretic m added. Hydrochlorothiazide, $12.5 \mathrm{mg}$ has been shown to provide an additive effect. After the addition diuretic, it may be possible to reduce the dose of Zestril. Diuretic Treated Patients: In hypertensive pat
who are currently being treated with a diuretic, symptomatic hypotension may occur occasionally follo who are currently being treated with a diuretic, symptomatic hypotension may occur occasionally follo
the initial dose of Zestril. The diuretic should be discontinued, if possible, for two or three days before begir the initial dose of Zestril. The diuretic should be discontinued, if possible, for two or three days before begir
therapy with Zestril to reduce the likelihood of hypotension. (See WARNINGS.) The dosage of Zestril st be adjusted according to blood pressure response. If the patient's blood pressure is not controlled with $Z$ alone, diuretic therapy may be resumed as described above. If the diuretic cannot be discontinued, an dose of $5 \mathrm{mg}$ should be used under medical supervision for at least two hours and until blood pressur administration of Zestril with potassium supplements, potassium salt substitutes, or potassium-sp diuretics may lead to increases of serum potassium. (See PRECAUTIONS.) Use in Elderly: In general, pressure response and adverse experiences were similar in younger and older patients given similar concentration time curve (AUC) are doubled in older patients so that dosage adjustments should be with particular caution. Dosage Adjustment in Renal Impairment: The usual dose of Zestril (10 m recommended for patients with creatinine clearance $>30 \mathrm{~mL} / \mathrm{min}$ (serum creatinine of up to approxim $3 \mathrm{mg} / \mathrm{dL}$ ). For patients with creatinine clearance $>10 \mathrm{~mL} / \mathrm{min} \leq 30 \mathrm{~mL} / \mathrm{min}$ (serum creatinine $\geq 3 \mathrm{mg}$ he recommended initial dose is $25 \mathrm{mg}$. The dosage may be titrated upward until blood pressure is cont or to a maximum of $40 \mathrm{mg}$ daily.

\begin{tabular}{|lcc|}
\hline Renal Status & Creatinine-Clearance $\mathrm{mL} / \mathrm{min}$ & Initial Dose mg/da \\
\hline $\begin{array}{l}\text { Normal Renal Function to Mild Impairment } \\
\text { Moderate to Severe Impairment }\end{array}$ & $>30$ & 10 \\
Dialysis Patents & $\geq 10 \leq 30$ & 5
\end{tabular}

Dialysis Patients

$<10$

Distributed by: Stuart Pharmaceuticals, Division of ICI Americas Inc, Wilmington, DE 19897. REFERENCES: 1. Zestrils (lisinopril) full prescribing information issued December 1987. 2. Ajayi AA, Campbe Kelman AW, et al: Pharmacodynamics and population pharmacokinetics of enalapril and lisinopril. Int J Clin Phar Res 1985;5(6):419-427. 3. Millar JA, Deriox FHM, McLean K, et al: Pharmacodynamics of converting enzyme inhib 4. Hodsman GP, Zabludowski JR, Zoccali C, et al: Enalapril (MK421) and its lysine analogue (MK521): A compar of acute and chronic effects on blood pressure, renin-angiotensin system and sodium excretion in normal man. Br Pharmacol 1984;17:233-241. 5. Physicians' Desk Reference, ed 42. Oradell, NJJ, Medical Economics Co, 1988. Vas
(enalapril maleate, MSD), pp 1406-1408. 6. Physicians' Desk Reference, ed 42. Oradell, NJ. Medical Economic

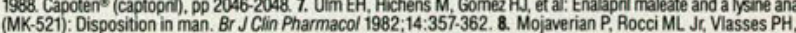
Effect of food on the 